\title{
Historical Nankai-Suruga megathrust earthquakes recorded by tsunami and terrestrial mass movement deposits on the Shirasuka coastal lowlands, Shizuoka Prefecture, Japan
}

\author{
Ed Garrett, 1,2 (D) Osamu Fujiwara, ${ }^{3}$ Svenja Riedesel, ${ }^{4}$ Jan Walstra, ${ }^{2}$ \\ Koen Deforce, 5,6 Yusuke Yokoyama, ${ }^{7}$ Sabine Schmidt, ${ }^{8}$ \\ Helmut Brückner, ${ }^{4}$ Marc De Batist, ${ }^{9}$ iD Vanessa MA Heyvaert, ${ }^{2,10}$ \\ and the QuakeRecNankai Team
}

\begin{abstract}
Geological investigations of coastal sediment sequences play a key role in verifying earthquake and tsunami characteristics inferred from historical records. In this paper, we present a multi-proxy investigation of a coastal lowland site facing the Nankai-Suruga megathrust and appraise evidence for tsunamis and earthquake-triggered terrestrial mass movements occurring over the last $\mathbf{8 0 0}$ years. Combining a high-resolution chronology with $\mathrm{X}$-ray computed tomography and analyses of particle size, diatoms, pollen, non-pollen palynomorphs and aerial photographs, we present the most compelling geological evidence of the I36I CE Kōan (also known as Shōhei) tsunami reported to date from any site along the megathrust. This finding is consistent with either of two recent hypotheses: a single larger rupture of both the Nankai and Tōnankai regions or two smaller ruptures separated by a few days. Enhancing the site chronology using Bayesian age modelling, we verify evidence for inundation during the 1498 CE Meio tsunami. While previous investigations identified evidence for historically recorded tsunamis in 1605, I707 and I854 CE and a storm surge in I680 or I699 CE, we encountered a thick sand layer rather than discrete extreme wave deposits in this interval. The overprinting of evidence highlights the potential for geological records to underestimate the frequency of these events. A terrestrial mass movement also deposited a sand layer at the site; radionuclide dating and aerial photographs provide independent confirmation that this may have been triggered by intense shaking in 1944 CE during the most recent great Nankai-Suruga megathrust earthquake.
\end{abstract}

\section{Keywords}

diatom, extreme wave event, landslide, palaeoseismology, palynomorph, radiocarbon, X-ray computed tomography

Received I3 August 2017; revised manuscript accepted 6 December 2017

\section{Introduction}

The Nankai-Suruga megathrust, the subduction zone lying to the south of the Japanese islands of Honshu, Shikoku and Kyushu, generates major and great earthquakes (moment magnitudes exceeding 7 and 8, respectively) on centennial or shorter timescales (Ando, 1975). Because of the densely populated and highly industrialised nature of the coastlines facing this subduction zone and the potential for earthquakes to trigger large tsunamis, future great earthquakes are considered to pose a major hazard to south central Japan (Central Disaster Management Council, 2012). The shortcomings of seismic hazard assessments based on historical records, highlighted by insufficient anticipation of the 2011 Tōhoku-oki earthquake on the Japan Trench subduction zone, have led to a renewed focus on longer geological records of past earthquakes and tsunamis (Goto et al., 2014; Kitamura, 2016). Palaeoseismology plays a key role in developing longer records and in verifying earthquake and tsunami characteristics inferred from historical records. Of particular importance along the Nankai-Suruga megathrust, palaeoseismic approaches may help to reveal rupture zone locations and the nature of fault segmentation
'Department of Geography and Institute of Hazard, Risk and Resilience, Durham University, Durham, UK

${ }^{2}$ Geological Survey of Belgium, Royal Belgian Institute of Natural

Sciences, Belgium

${ }^{3}$ Geological Survey of Japan, National Institute of Advanced Industrial

Science and Technology, Japan

${ }^{4}$ Institute of Geography, University of Cologne, Germany

${ }^{5}$ Flanders Heritage Institute, Belgium

${ }^{6} \mathrm{OD}$ Earth and History of Life, Royal Belgian Institute of Natural

Sciences, Belgium

${ }^{7}$ Atmosphere and Ocean Research Institute, The University of Tokyo,

Japan

8 UMR5805 EPOC, University of Bordeaux, France

${ }^{9}$ Renard Centre of Marine Geology, Department of Geology, Ghent

University, Belgium

${ }^{10}$ Department of Geology, Ghent University, Belgium

\section{Corresponding author:}

Ed Garrett, Department of Geography, Durham University, South Road, Durham DHI 3LE, UK.

Email: edmund.garrett@durham.ac.uk 
(Garrett et al., 2016; Satake, 2015). The inferred rupture zones of recent and historical earthquakes indicate along-strike fault segmentation and the existence of a variety of rupture modes (Ando, 1975). Nevertheless, considerable debate remains over the locations and magnitudes of the majority of pre-18th century earthquakes, despite the importance of this evidence for assessing seismic and tsunami hazards.

Abruptly emplaced coarse-grained sediments preserved in lowlands and lakes located along coastlines facing the NankaiSuruga megathrust record evidence for tsunami inundation, mass movements and liquefaction triggered by earthquakes and also for other non-seismically triggered extreme wave events (Garrett et al., 2016 and references therein). In this study, we investigate a coastal lowland site at Shirasuka, located on the Enshu-nada coastline of Shizuoka Prefecture (Figure 1). We seek to provide further information on earthquakes and tsunamis recorded here during the historical period and to explore the consequential implications for understanding rupture zones, fault segmentation and earthquake recurrence. Komatsubara et al. (2008) previously investigated the site and reported seven abruptly emplaced sand layers, variously attributing them to tsunamis, storm surges and terrestrial processes occurring over the last $\sim 700$ years. In this paper, we aim to (1) refine the site chronology and test the proposed correlation of sedimentary evidence with the historical record; (2) use a multi-proxy approach to characterise the deposits, with a focus on distinguishing different formation mechanisms; (3) describe the terrestrially derived deposits and investigate the potential for earthquaketriggered mass movements; and (4) assess the contribution of the palaeoseismic record at Shirasuka to understanding past earthquakes along the Nankai-Suruga megathrust.

\section{Study area}

\section{Tectonic setting}

The Shirasuka lowlands lie on the Enshu-nada coastline of south central Honshu (Figure 1). The lowlands face the Nankai-Suruga megathrust, the subduction zone that marks the descent of the Philippine Sea Plate beneath the Eurasian Plate. With convergence at rates averaging 40-55 $\mathrm{mm} \mathrm{yr}^{-1}$ (Loveless and Meade, 2010; Mazzotti et al., 2000) and a high degree of interseismic coupling (Loveless and Meade, 2016; Ozawa et al., 1999), the subduction zone is known to generate great megathrust earthquakes. These earthquakes are characterised by intense longduration shaking, crustal deformation and tsunami generation. Historical records provide a detailed chronology of past NankaiSuruga earthquakes, supporting the existence of fault segmentation and variability in rupture lengths (Ando, 1975). Over the last one and a half millennia, 11 tsunamigenic great earthquakes ruptured the subduction interface: in $684,887,1096,1361,1498$, 1605, 1707, 1854 (twice), 1944 and 1946 CE. Of these, the second earthquake of 1854 and the 1946 rupture only incorporated slip in the western Nankai region, with the first 1854 earthquake and the 1944 rupture restricted to the eastern Tónankai region (Ando, 1975; Ishibashi and Satake, 1998; Seno, 2012). While historical and geological records support a full-length rupture in 1707, the rupture zones of earlier earthquakes are less well constrained and are the subject of continued debate (Garrett et al., 2016; Satake, 2015; Seno, 2012).

\section{Other extreme wave events}

In addition to tsunamis, the Pacific coast of south central Japan is also impacted by storm surges generated by typhoons. Between 1951 and 2016 CE, 216 typhoons passed within $300 \mathrm{~km}$ of the Tōkai region (Japan Meteorological Agency, 2017). Historical documents record destructive storm surges impacting the Enshunada coastline associated with typhoons in 1498, 1499, 1510, 1680 and 1699 CE. Storm surges associated with two typhoons in early and late August 1498 flooded fields and destroyed houses along the Enshu-nada coastline (Shizuoka Prefecture, 1996). The 1499 storm caused $\sim 800$ fatalities around Hamamatsu and flooded the Tōkaidō highway connecting Edo (modern-day Tokyo) with Kyoto. The 1510 storm surge broke through the coastline separating Lake Hamana from the sea (Figure 1) (Shizuoka Prefecture, 1996). Multiple typhoons struck in 1680 , with the most severe occurring on 28th September, accompanied by a $2.7 \mathrm{~m}$ high storm surge and resulting in $\sim 300$ fatalities. Further typhoons again resulted in flooding and multiple fatalities along the Enshu-nada coastline in 1699 (Shizuoka Prefecture, 1996). During the instrumental period, Typhoon Tess made landfall on the Enshu-nada coastline in 1953, dramatically widening the connection between Lake Hamana and the sea (Mazada, 1984).

\section{Site setting and previous research}

The study site at Shirasuka consists of a 100-m wide coastal lowland separated from the Pacific by a $\sim 10 \mathrm{~m}$ high dune ridge and backed by the $60-80 \mathrm{~m}$ high riser of the middle Pleistocene Tenpakubara terrace (Figure 1). The terrace comprises rounded gravel-sized chert and sandstone clasts in a micaceous sand and mud matrix (Isomi and Inoue, 1969; Sugiyama, 1991). The construction of the Shiomi By-pass of Japan National Route 1, a major highway linking Tokyo and Hamamatsu to the east with Nagoya to the west, may have artificially increased the height of the contemporary dune ridge in the early 21 st century. The surface of the lowlands lies at an elevation of approximately $4 \mathrm{~m}$ above mean sea level. The Enshu-nada coastline is microtidal, with a maximum tidal range of $1.5 \mathrm{~m}$ at the mouth of Lake Hamana (Mustari et al., 2012).

Investigating the sedimentary infill at Shirasuka using a geoslicer, Fujiwara et al. (2006) identified a change in environment from a wave-dominated beach to an organic-rich back marsh enclosed by a beach ridge. The transition from beach to marsh occurred during the 13th century $\mathrm{CE}$, with a subsequent change after the 16th century seeing greater infilling of the marsh by washover sand and material from the terrace. The site is currently intermittently used for rice cultivation. Investigating a total of 11 geoslicer locations, including those reported in the initial study, Komatsubara et al. $(2006,2008)$ identified seven discrete sand layers of varying lateral extent and thickness (coring locations in Figure 1). Based on sedimentary structures, grain-size analysis and mineralogical composition, Komatsubara et al. (2008) attributed four of the sand layers to the 1498, 1605, 1707 and 1854 tsunamis; one layer to a storm surge in 1680 or 1699; and two layers to sediment mobilised from the mid-Pleistocene terrace at the landward boundary of the site. The four inferred tsunami deposits are characterised by massive or parallel-laminated structures, intraclasts and draping mud layers, while the storm surge deposit consists of thin current ripple laminated sand layers. The terrestrially sourced deposits also display parallel lamination, intraclasts and draping mud layers; however, unlike the tsunami deposits, they are also mica rich.

\section{Materials and methods}

\section{Sampling and sedimentology}

Guided by the stratigraphic results of previous investigations, we took six cores from within a radius of $\sim 1 \mathrm{~m}$ from $34.67807^{\circ} \mathrm{N}$ $137.50487^{\circ} \mathrm{E}$ using an Atlas Copco Cobra TT vibracorer and hydraulic core extractor (Figure 1). Each core consists of between two and four core sections, each of up to $1 \mathrm{~m}$ in length. The coring strategy, involving a large number of cores from a highly restricted spatial area, was an attempt to mitigate against the effects of core hole collapse. Furthermore, repeated overlapping core sections 

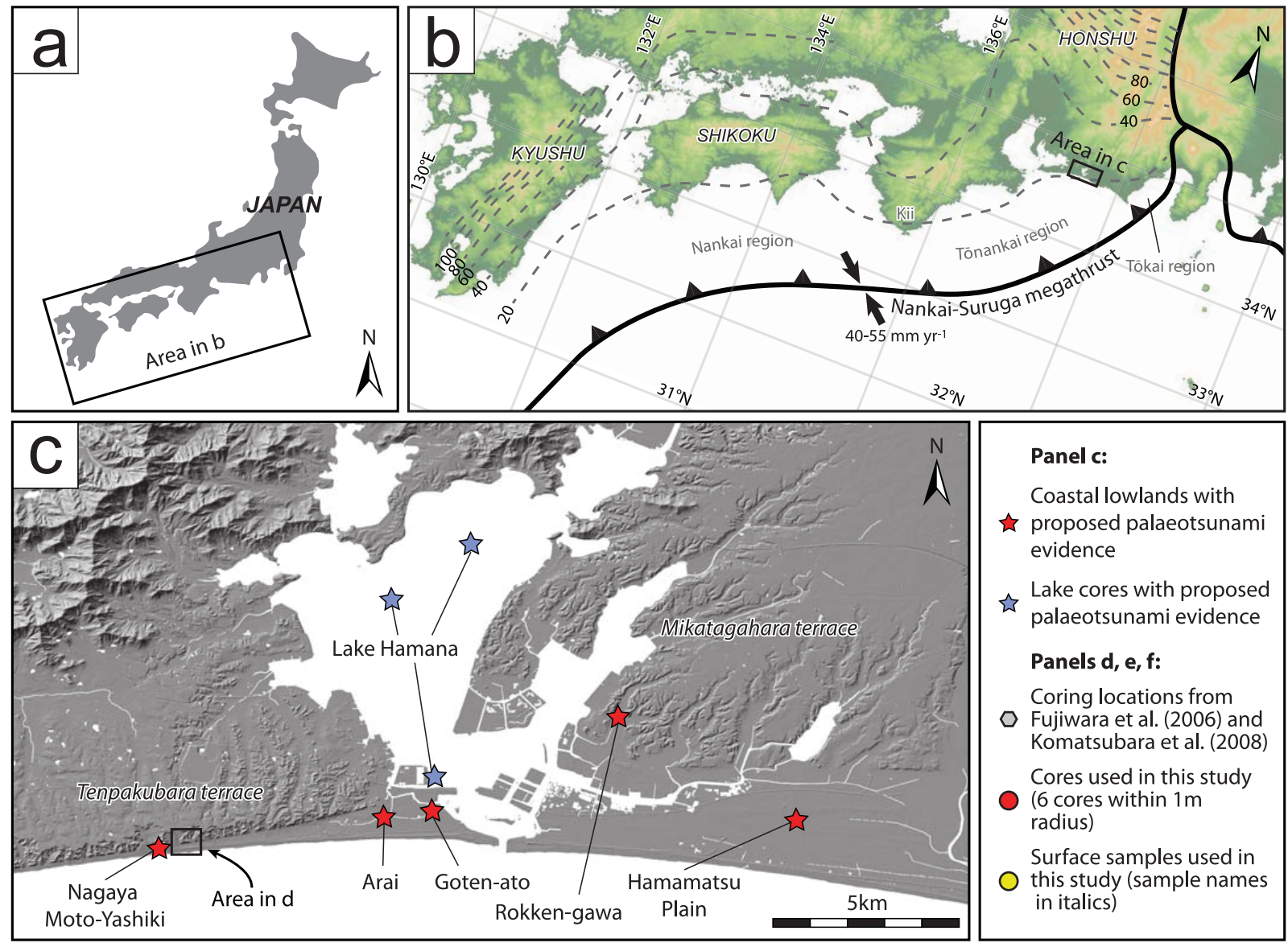

Panel c:

Coastal lowlands with

s proposed palaeotsunami evidence

$\{$ Lake cores with proposed palaeotsunami evidence

Panels d, e, f:

Coring locations from

0 Fujiwara et al. (2006) and Komatsubara et al. (2008) Cores used in this study

(6 cores within $1 \mathrm{~m}$ radius)

Surface samples used in

$O$ this study (sample names in italics)

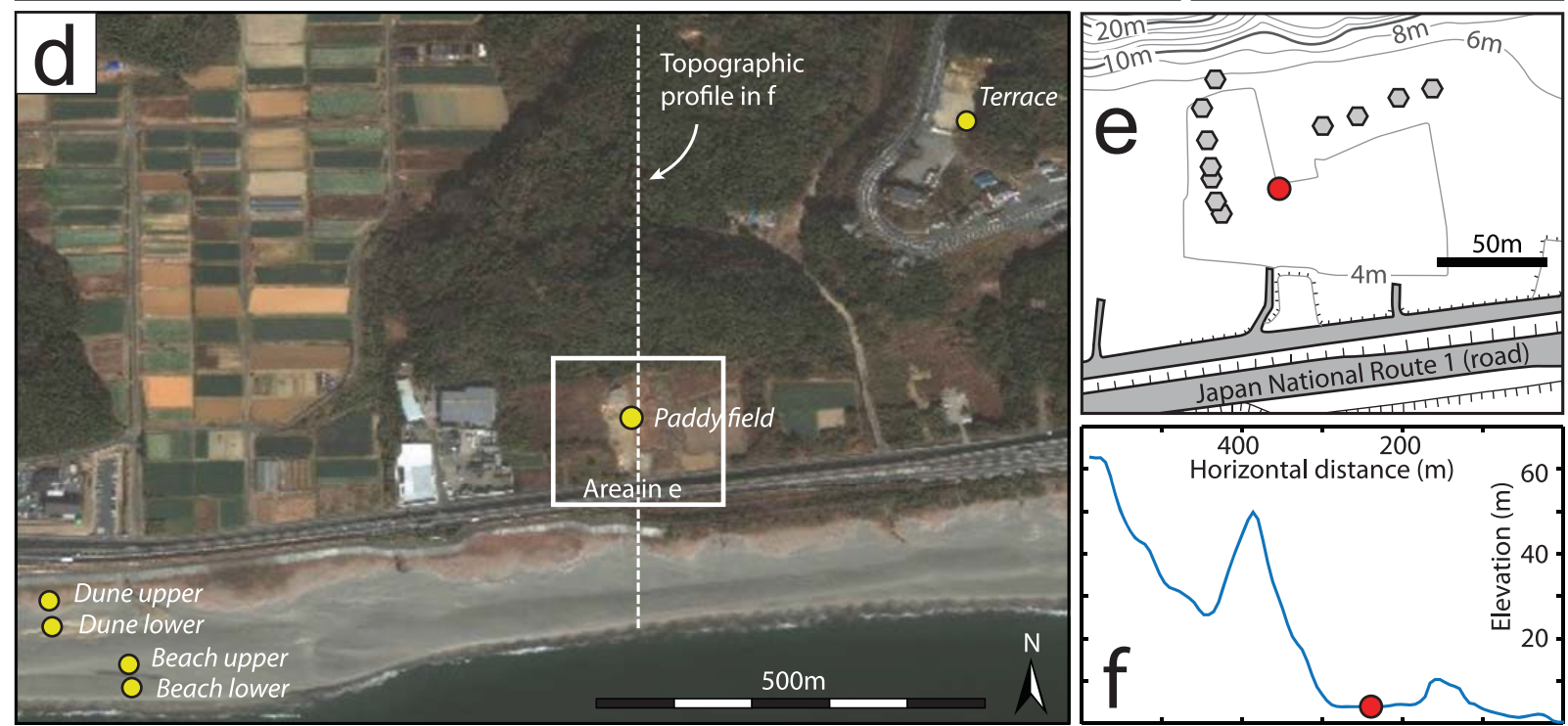

Figure I. (a) Japan, including (b) the tectonic setting of the Nankai-Suruga megathrust. Dashed grey lines mark $20 \mathrm{~km}$ interval contours of the upper boundary of the subducting Philippine Sea slab (Baba et al., 2002; Hirose et al., 2008; Nakajima and Hasegawa, 2007). (c) The central Enshu-nada coastline, including the locations of sites with proposed palaeoseismic evidence (see Garrett et al., 2016 and references therein). Digital elevation data provided by the Geographical Survey Institute (https://fgd.gsi.go.jp/download/menu.php). (d) The site at Shirasuka, including the surface sample locations from this study. Background image from WorldView-2, DigitalGlobe (2013). (e) The coring locations used in this and in previous studies (Fujiwara et al., 2006; Komatsubara et al., 2006, 2008). (f) Topographic profile based on elevation data in (c), $5 \times$ vertical exaggeration.

minimised stratigraphic uncertainties resulting from differential compaction of strata in a location characterised by alternating layers of humic mud and unconsolidated sand.

We recovered six surface samples from locations close to the coring site (Figure 1). These samples allow us to provide an initial characterisation of sediments from the modern beach (two samples), dune ridge (two samples), paddy field (one sample) and mid-Pleistocene terrace (one sample).
To investigate sedimentary structures, we scanned selected core sections using the medical X-ray computed tomography (CT) scanner at Ghent University Hospital (Siemens SOMATOM Definition Flash). As sediment composition, density and grain size influence X-ray attenuation, this approach assists with visualising sedimentary structures (Cuven et al., 2013; Ikehara et al., 2014; May et al., 2016). The scanner operated at $120 \mathrm{kV}$, with an effective mAs of 200 and a pitch of 0.45 . The reconstructed 
images represent $0.6 \mathrm{~mm}$ of sediment, and have a pixel size of 0.2 $\mathrm{mm}$ and a down-core step size of $0.6 \mathrm{~mm}$. We used VGStudio 2.0 to visualise the datasets.

We based sedimentological observations on X-ray CT scans and visual analysis of split cores. Laser diffraction using a Beckman Coulter LS 13320 particle size analyser with aqueous liquid module provided grain-size distributions for sand-rich intervals from cores JSH1/F, JSH3/F and JSH3/O and the six surface samples. We analysed 5-mm-thick samples at 5- or 10-mm intervals. Sample preparation involved the addition of hydrogen peroxide to remove organic matter, with sodium hexametaphosphate used as a dispersant. We analysed grain-size distributions using the geometric method of moments in GRADISTAT v.4 (Blott and Pye, 2001).

\section{Chronology}

We refine the site chronology using AMS radiocarbon and shortlived radionuclide dating approaches. We have obtained 28 new radiocarbon ages from cores JSH1/O, JSH1b/F, JSH3/F and $\mathrm{JSH} 3 / \mathrm{O}$, with analysis undertaken at the Atmosphere and Ocean Research Institute, the University of Tokyo facility. Single stage accelerator mass spectrometry was used to obtain radiocarbon ages (Hirabayashi et al., 2017), with graphitisation completed using the protocol described by Yokoyama et al. (2007, 2010); nine dates are from above-ground parts of terrestrial plants. As few suitable fragile plant macrofossils were encountered in key intervals above and below sand-rich layers, the remaining ages relate to wood fragments (three samples), acid insoluble organic (AIO) fractions (13 samples) or bulk samples (three samples). The AIO samples were sieved at $180 \mu \mathrm{m}$ to remove downwardpenetrating roots, while the bulk samples relate to the full spectrum of particle sizes. We report dates as ${ }^{14} \mathrm{C}$ yr BP and calibrate to calendar years prior to $1950 \mathrm{CE}$ using OxCal v.4.2 (Bronk Ramsey, 2009) and the IntCal13 calibration curve (Reimer et al., 2013). The stratigraphic ordering of samples enables the development of age models using a Sequence approach in OxCal (Bronk Ramsey, 1995; Lienkaemper and Ramsey, 2009). We present all calibrated ages and modelled posterior distributions as $2 \sigma$ ranges in years $C E$.

We use short-lived radionuclides, ${ }^{210} \mathrm{~Pb}\left(\mathrm{~T}_{1 / 2}=22.3\right.$ years $)$ and ${ }^{137} \mathrm{Cs}\left(\mathrm{T}_{1 / 2}=30\right.$ years $)$, to further constrain the chronology for the upper part of the stratigraphic sequence. Activities of radionuclides were measured in sediment samples from the upper $60 \mathrm{~cm}$ of core JSH3/F, excluding a prominent sand layer. Activities of ${ }^{210} \mathrm{~Pb},{ }^{226} \mathrm{Ra}$ and ${ }^{137} \mathrm{Cs}$ were measured using a lowbackground, high-efficiency, well-shaped Ge detector. Excess ${ }^{210} \mathrm{~Pb}\left({ }^{210} \mathrm{~Pb}_{\mathrm{xs}}\right)$ was calculated by subtracting the activity supported by its parent isotope, ${ }^{226} \mathrm{Ra}$, from the total ${ }^{210} \mathrm{~Pb}$ activity in the sediment. Errors are based on $1 \sigma$ counting statistics. The most widely used models for calculating sedimentation rates or ages from ${ }^{210} \mathrm{~Pb}_{\mathrm{xs}}$ profiles are Constant Initial Concentration, Constant Rate of Supply or Constant Flux-Constant Sedimentation (CF:CS) (Appleby and Oldfield, 1978). Considering the low ${ }^{210} \mathrm{~Pb}_{\mathrm{xs}}$ activities, we have selected the CF:CS model, which has the effect of smoothing minor variability (Appleby, 1998). Errors on ages were calculated by propagating the error on the sedimentation rate. The ${ }^{137} \mathrm{Cs}$ profile was used as an independent time marker.

\section{Microfossil analysis}

To assess the provenance of the sand layers reported by Komatsubara et al. (2008), we analysed the assemblages of selected microfossil groups. Diatoms and foraminifera have been widely used to identify transport and deposition by tsunamis (see reviews by Dura et al., 2016; Pilarczyk et al., 2014). Diatom assemblages in tsunami deposits in onshore locations often contain an elevated proportion of marine species (Dawson et al., 1996; Hemphill-Haley, 1996; Nanayama et al., 2007), although assemblages are frequently a mix of marine, brackish and freshwater species (Garrett et al., 2013; Sawai et al., 2009) and largely freshwater assemblages have also been recorded (Cisternas et al., 2017; Nelson et al., 2015; Szczuciński et al., 2012). Storm surge deposits may similarly exhibit marine or mixed diatom assemblages (e.g. Parsons, 1998). Identification of allochthonous foraminifera in freshwater depositional settings can also provide a valuable criterion for identifying marine inundations (e.g. Hippensteel and Martin, 1999; Pilarczyk et al., 2012). Pollen and non-pollen palynomorphs have more rarely been used to identify extreme wave events and associated environmental changes (e.g. Grand Pre et al., 2012; Nanayama et al., 2007; Tuttle et al., 2004). Bondevik et al. (1998) encountered abundant marine dinoflagellate cysts alongside freshwater algal taxa in a deposit emplaced by the Storegga tsunami in an emerged coastal basin in western Norway. Goff et al. (2010) recorded an increase in pollen from salt-tolerant plant species and brackish water dinoflagellate cysts suggesting an environmental change following marine inundation of a coastal wetland in New Zealand. Brackish and marine dinoflagellate cysts were also present in an inferred tsunami deposit, suggesting the marine origin of the sediments.

Analyses presented here focussed on diatoms, pollen and non-pollen palynomorphs. Samples prepared for foraminiferal assemblage analysis yielded no tests, potentially as a consequence of carbonate dissolution in an acidic environment (Murray and Alve, 1999). We prepared samples from cores JSH3/F and $\mathrm{JSH} 3 / \mathrm{O}$ for diatom analysis using standard procedures (Palmer and Abbott, 1986). Focussing on sand layers and the immediately overlying and underlying sediments, we analysed 5-mm-thick samples at 20- to 50-mm intervals and identified at least 250 diatoms per sample. Nomenclature followed Kobayasi (2006), Hartley et al. (1996), Sawai and Nagumo (2003) and Chiba et al. (2016). We summarise diatom assemblages into five groups based on their tolerance to salinity (cf. Hemphill-Haley, 1993; Lowe, 1974; Van Dam et al., 1994): marine, brackish, freshwater (low salinity), freshwater (salt tolerant) and freshwater (salt intolerant).

We analysed pollen and non-pollen palynomorphs from a total of 15 fossil samples from cores JSH3/F and JSH3/O and the contemporary surface of the paddy field. Samples were processed using standard techniques for pollen analysis (Moore et al., 1991). Identifications are based on Beug (2004) and Demske et al. (2013) for pollen and Van Geel $(1978,2001)$ for other palynomorphs. We present the data as percentages relative to the sum of all terrestrial pollen types.

\section{Geospatial data}

To investigate the occurrence and timing of recent terrestrial mass movements, we analysed aerial photographs taken in August 1947 (US Air Force sortie M415-1, scale 1:40,000) and May 1959 (Geographical Survey Institute, sortie P28, scale 1:28,000), accessed through the online data service of the Geographical Survey Institute (http://maps.gsi.go.jp). The photographs were orthorectified and analysed using Imagine OrthoBASE Pro 8.6 and Stereo Analyst 1.3 (Leica Geosystems, 2002a, 2002b).

\section{Results}

\section{Stratigraphy and sedimentology}

The six newly acquired cores from Shirasuka reveal four sand layers interbedded with organic muds (Figure 2). Our correlation of the sand layers between the closely spaced cores is based on the depth of each sand layer, estimates of compaction during coring and the presence of distinct sedimentary structures. We refer to 


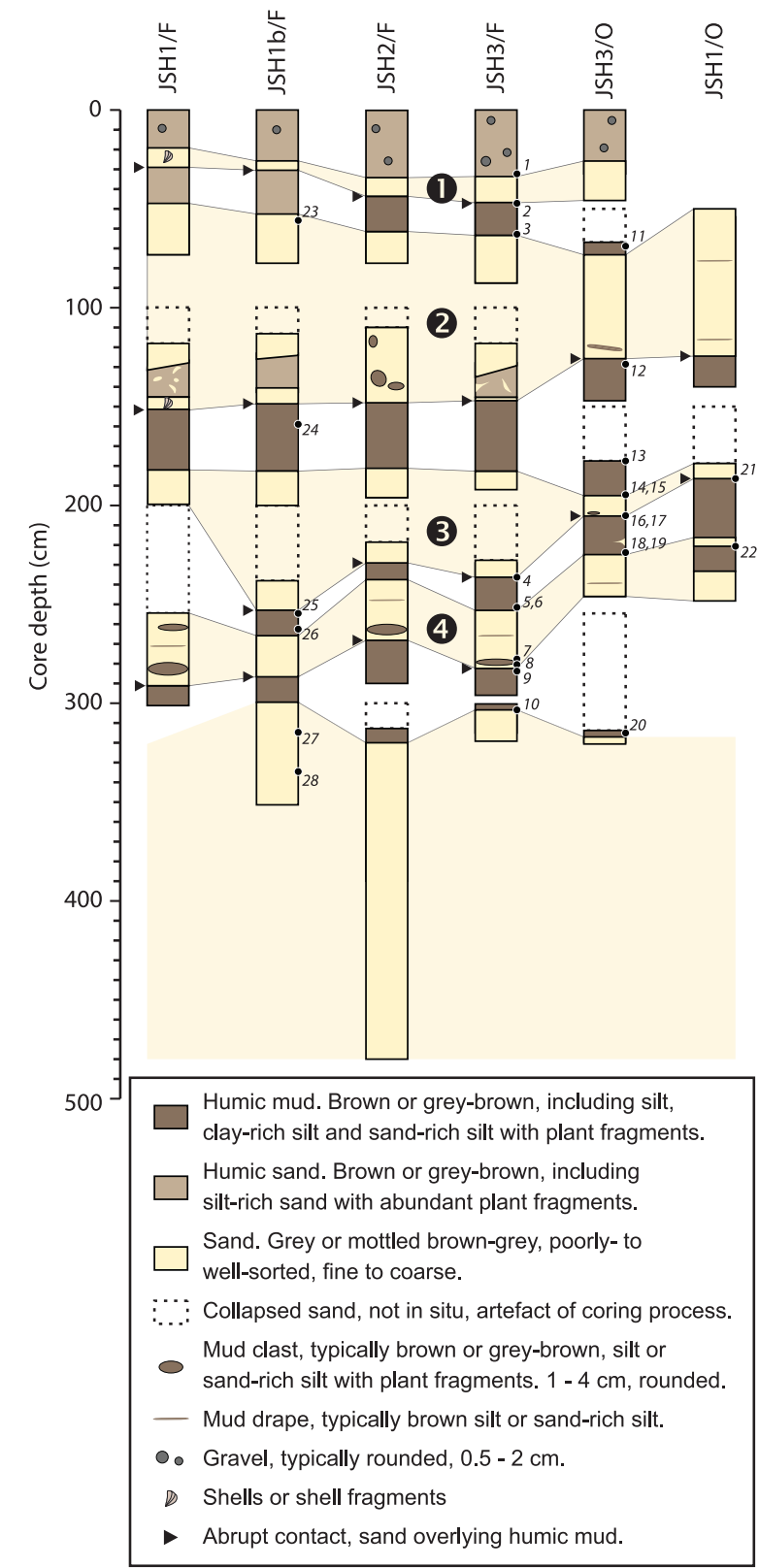

Figure 2. Stratigraphy of the six cores from Shirasuka, each taken from within a $\sim 1 \mathrm{~m}$ radius of $34.67807^{\circ} \mathrm{N} 137.50487^{\circ} \mathrm{E}$. Numbers in circles refer to the four identified sand layers. Italicised numbers refer to radiocarbon samples listed in Table $I$.

these sand layers as Sands 4, 3, 2 and 1, with Sand 1 the closest to the present surface. The sequence of sand and organic mud layers is underlain by cross-stratified medium to very coarse sand (referred to as the basal sand as it could not be cored beneath).

Sand 4. The lowermost sand layer, a mottled brown-grey sand with silt-rich intervals, is encountered at a depth of between 250 and $300 \mathrm{~cm}$ below the ground surface (Figure $3 \mathrm{~d}$ ). In core JSH3/F, Sand 4 can be subdivided into five subunits: (1) a 10-cm-thick upper unit of well-sorted medium sand, (2) a 3-cm-thick drape of very poorly sorted sand-rich silt, (3) a 10-cm-thick middle unit of poorly sorted fine to medium sand, (4) a 4-cm-thick layer of very poorly sorted sand-rich medium to coarse silt, and (5) a $1.5-\mathrm{cm}-$ thick lower unit of very poorly sorted fine sand. Grain-size data from core JSH3/F indicate the upper sand subunit fines upwards from a median size of $\sim 290$ to $\sim 220 \mu \mathrm{m}$, while the middle sand subunit coarsens upwards from a median size of $\sim 200-250 \mu \mathrm{m}$. Visual inspection and X-ray CT scans of core JSH3/F suggest that subunit 4 is a large and rounded mud clast. The lower contact dividing Sand 4 from the underlying organic silt is abrupt in all of the cores, while the upper contact is moderate to abrupt.

Sand 3. At a depth of around $200 \mathrm{~cm}$ below the contemporary surface, Sand 3 consists of mottled brown-grey silt-rich sand (Figure 3c). In the one core that spans both the lower and upper contacts, JSH3/O, the layer is $10 \mathrm{~cm}$ thick. Grain-size data from core JSH3/O indicate a median size of 220-250 $\mu \mathrm{m}$ for the lower $8 \mathrm{~cm}$, which does not display grading, with a 2-cm-thick cap of coarser material (median 260-290 $\mu \mathrm{m}$ ). The coarse cap, highlighted by higher X-ray attenuation in CT scans of core JSH3/O, is poorly sorted, while the lower $8 \mathrm{~cm}$ are very poorly sorted. The lower and upper contacts are abrupt in all cores and centimetrescale mud clasts are present within the lowermost $2 \mathrm{~cm}$. Welldefined regions of lower X-ray attenuation indicate the presence of subhorizontally bedded plant fragments in core JSH3/O.

Sand 2. The majority of the sediment recovered between 50 and $150 \mathrm{~cm}$ below the modern surface consists of mottled brown-grey sand. As consistent subdivision was not possible across the six cores, we group this sand-rich interval and its siltier and more organic subunits as Sand 2 (Figure 3b). Only one of the six cores, JSH3/O, includes a single section encompassing both the lower and upper contacts of this sand layer; in this section, the layer is $50 \mathrm{~cm}$ thick. Grain-size data from core JSH1/F indicate Sand 2 consists of medium sand with silt-rich medium sand intervals. The layer displays no vertical grading, with median grain sizes of $200-280 \mu \mathrm{m}$ and consistently poor or very poor sorting. The contact with the underlying organic silt is abrupt in all cores, while the upper contact is typically gradual. X-ray CT scans of core JSH3/O reveal complex and chaotic structures within the deposit, including subhorizontal layering (Figure 3b). Intervals of lower attenuation and finer, more poorly sorted grain-size distributions indicate the presence of mud-rich layers.

Sand $I$. The uppermost sand layer, lying between 20 and $50 \mathrm{~cm}$ below the modern surface, consists of mottled brown-grey medium sand (Figure $3 \mathrm{a}$ ). In the four core sections that span the layer, the thickness ranges from 5 to $14 \mathrm{~cm}$. The lower contact with the underlying dark brown sand- and organic-rich silt is abrupt in all cores. The upper contact with the overlying dark brown silt- and organic-rich fine to medium sand is also identifiably abrupt through visual analysis, but less distinct in CT scans. Grain-size data from core JSH3/F indicate a median size of 250 $300 \mu \mathrm{m}$, with a slight coarsening-upwards trend. The layer is moderately to moderately well sorted. While no mud clasts or drapes are apparent, CT scans of core JSH3/F show that the deposit is not entirely homogeneous. Between 41 and $47 \mathrm{~cm}$, the presence of several regions of greater attenuation (lighter grey voxels) suggests weak centimetre-scale layering. This may reflect grain-size variations missed by the coarser sampling resolution of the grain-size analysis $(0.5-1 \mathrm{~cm})$ or variations in density or mineralogy.

Surface samples. The four samples from the contemporary beach and dune (see Figure 1 for locations) consist of moderately wellsorted medium sand (Figure 3e). The lower beach and upper dune samples share median grain sizes of $\sim 365 \mu \mathrm{m}$, while the upper beach and lower dune samples are finer, with median sizes of 265 and $310 \mu \mathrm{m}$, respectively. The minerogenic component of the paddy field sample consists of very poorly sorted medium silt with a median of $\sim 50 \mu \mathrm{m}$. The paddy field sediment also contains abundant plant fragments and humified plant remains. The terrace displays a diverse range of grain sizes and sedimentary structures, including imbricated rounded gravels to $5 \mathrm{~cm}$ and cross-bedded 
a. Sand 1 (core JSH3/F)

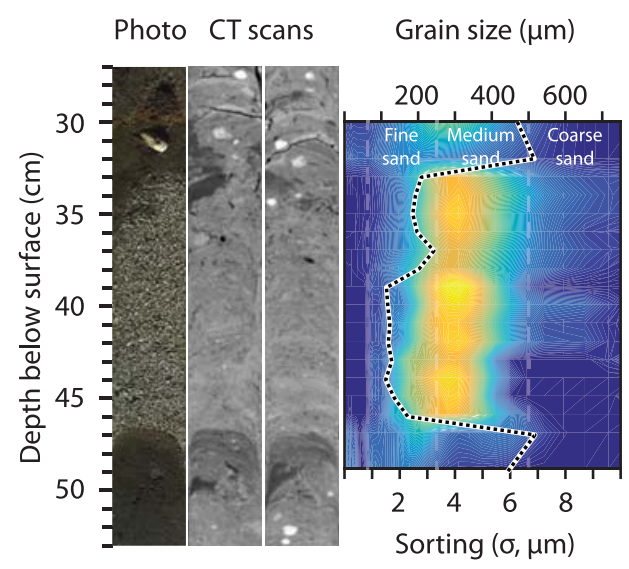

b. Sand 2 (CT from JSH3/O, grain size from core JSH1/F)

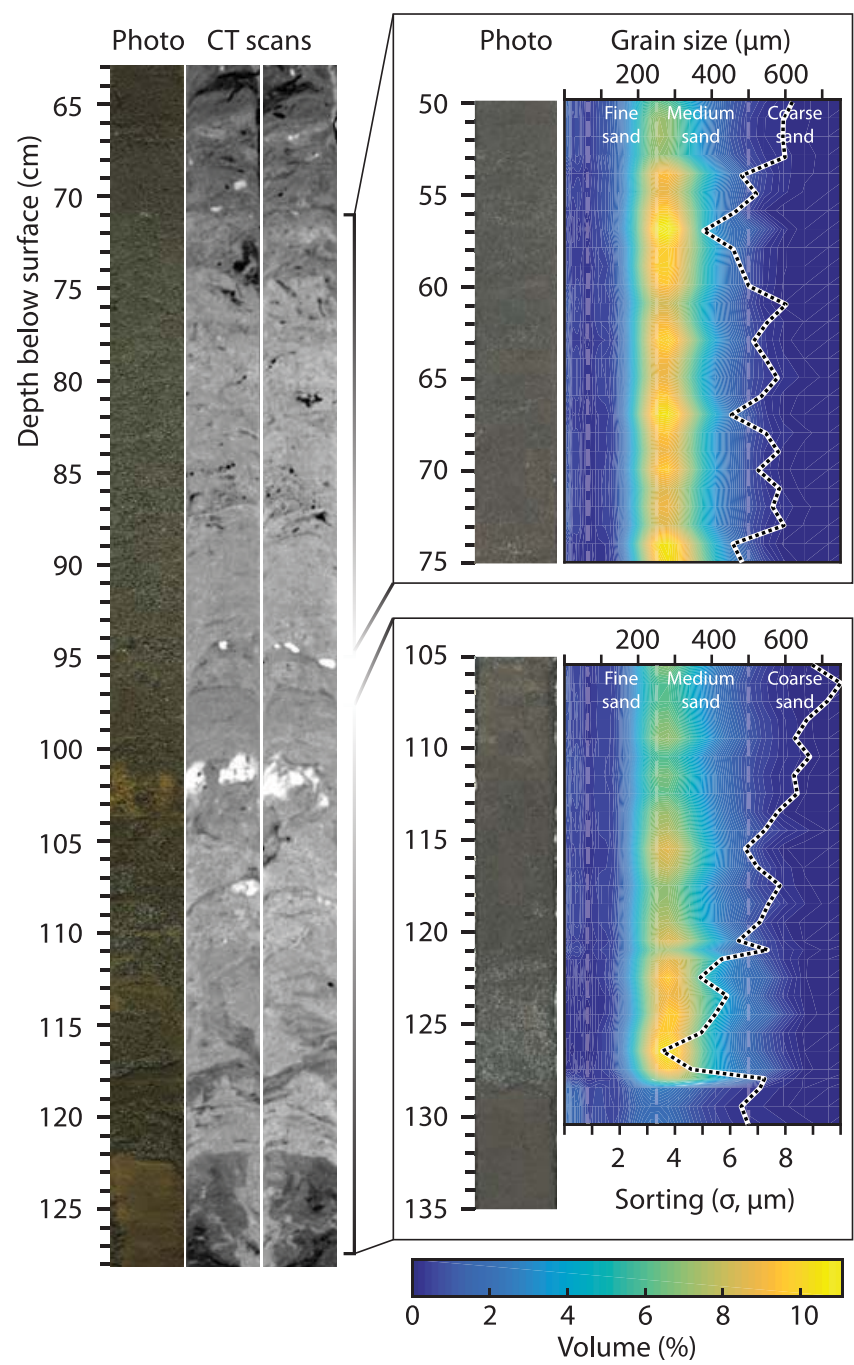

C. Sand 3 (core JSH3/O)

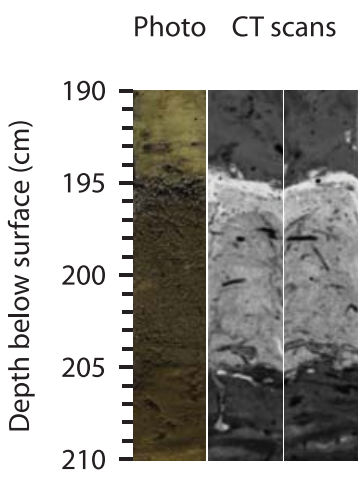

d. Sand 4 (core JSH3/F) Photo CT scans

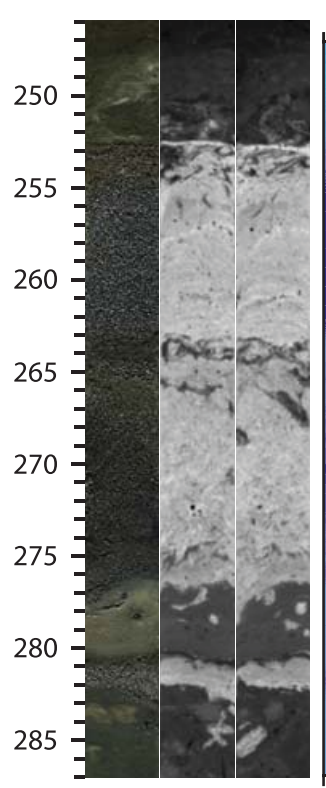

Grain size $(\mu \mathrm{m})$
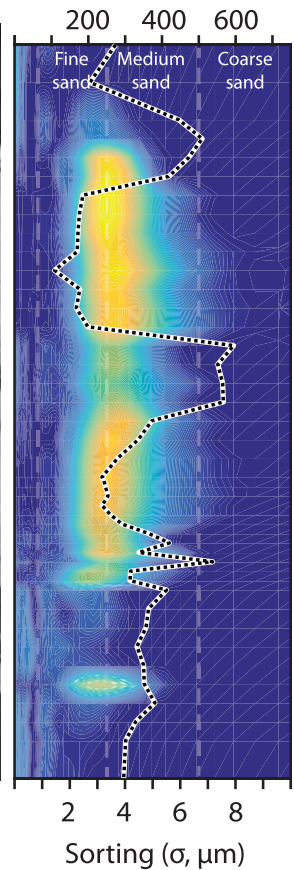

\section{Q. Modern samples}

Grain size $(\mu \mathrm{m})$

$200 \quad 400 \quad 600$

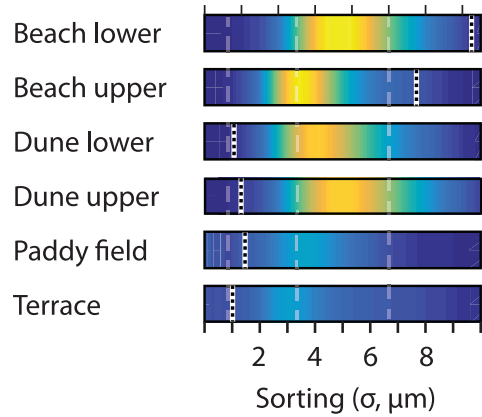

Figure 3. (a-d) Linescan photographs, frontal and sagittal X-ray CT views, and grain-size distributions for Sands I to 4. (e) Modern sample grain-size distributions.

coarse sand units. The single available terrace sample consists of poorly sorted medium silt (median of $\sim 55 \mu \mathrm{m}$ ).

\section{Microfossils}

Diatoms. Our diatom analysis identified 165 species in 41 samples taken from the four sand layers and the immediately overlying and underlying organic mud units. Salt-tolerant freshwater species dominate the assemblage in every sample (Figure 4). Sands 4, 3 and 2 contain Pseudostaurosira elliptica at abundances frequently in excess of $50 \%$ and, in the case of samples from Sand 2, in excess of $95 \%$ of the total diatom count. P. elliptica occurs in Sand 1 at lower abundances, with other salt-tolerant freshwater species, including Staurosira construens and $S$. construens var. venter, also present. The latter is the most commonly encountered species in one sample from this sand layer. In 


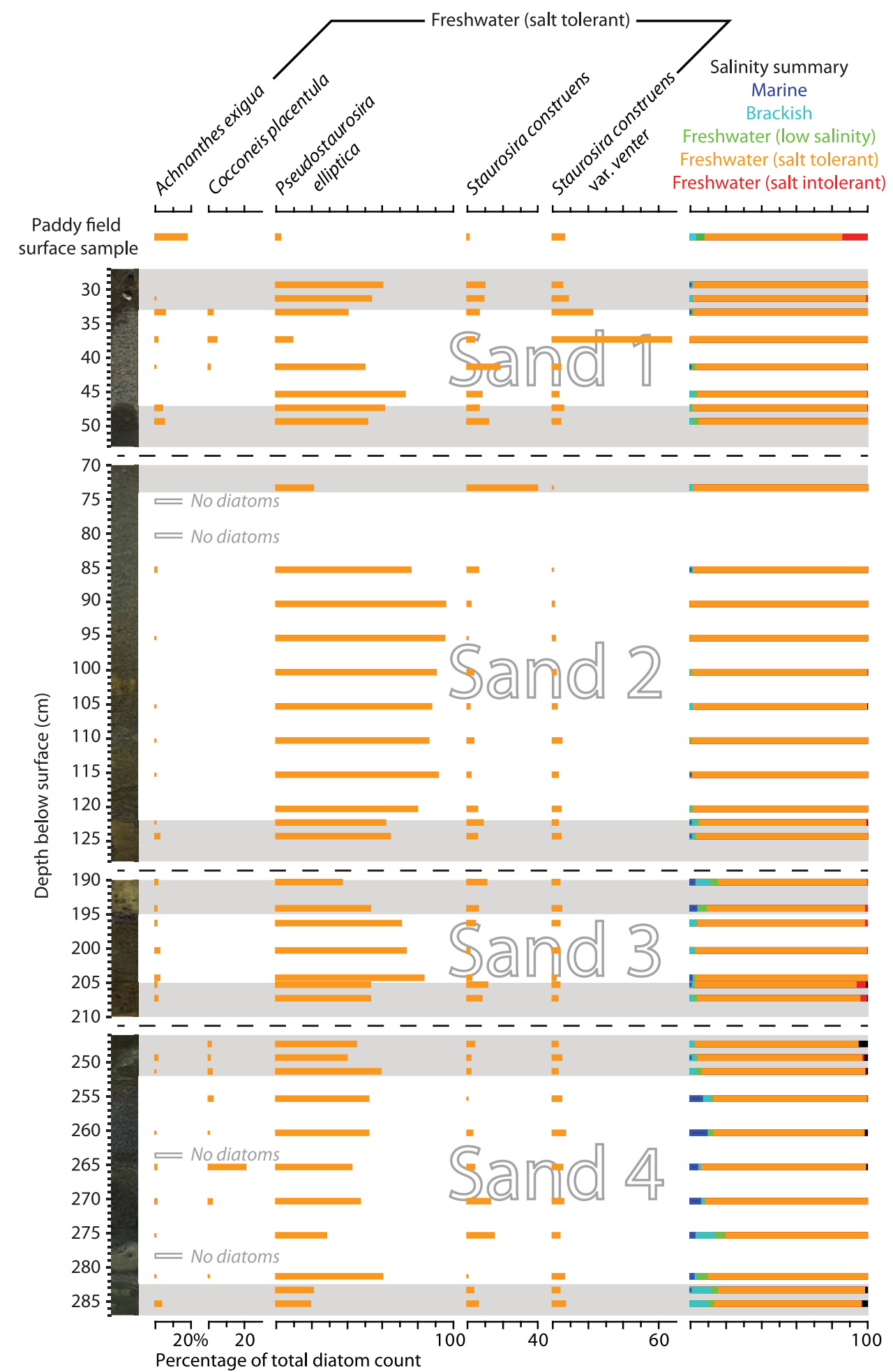

Figure 4. Summary of diatom assemblages (species exceeding $10 \%$ in one or more sample) from the four sand layers and intervening humic mud layers and the paddy field surface sample. Sands I and 4 sampled in core JSH3/F; Sands 2 and 3 sampled in core JSH3/O.We did not encounter any diatoms in the beach, dune or terrace surface samples.

Sand 4 , the contribution of marine and brackish taxa peaks at $\sim 9 \%$, with Fallacia tenera and Ctenophora pulchella the most frequently identified higher salinity species. The percentage of marine and brackish species is consistently less than $3 \%$ in Sands 3,2 and 1 , and no diatoms from these salinity groups are encountered in seven of the 15 samples from these layers. The organic mud units between the sand layers are dominated by salt-tolerant freshwater species, including $P$. elliptica at abundances of between $20 \%$ and $65 \%$.

No diatoms were found in the five surface samples from the beach, dune and terrace. The sample from the surface of the paddy field contains 39 species, of which 31 are also found in the fossil samples. The three freshwater categories include over $96 \%$ of the modern assemblage, with the remaining $4 \%$ brackish and no marine species encountered. Only one species, Achnanthes exigua, exceeds $10 \%$ of the assemblage, with the dominant fossil species, P. elliptica, contributing less than $3 \%$.

Pollen and non-pollen palynomorphs. Exploratory pollen analysis focussed on Sands 4, 3 and 1 and the organic silt units above and below Sand 3 (Figure 5). Fifteen fossil samples yielded 20 arboreal and 20 non-arboreal pollen taxa, eight freshwater aquatic taxa, 


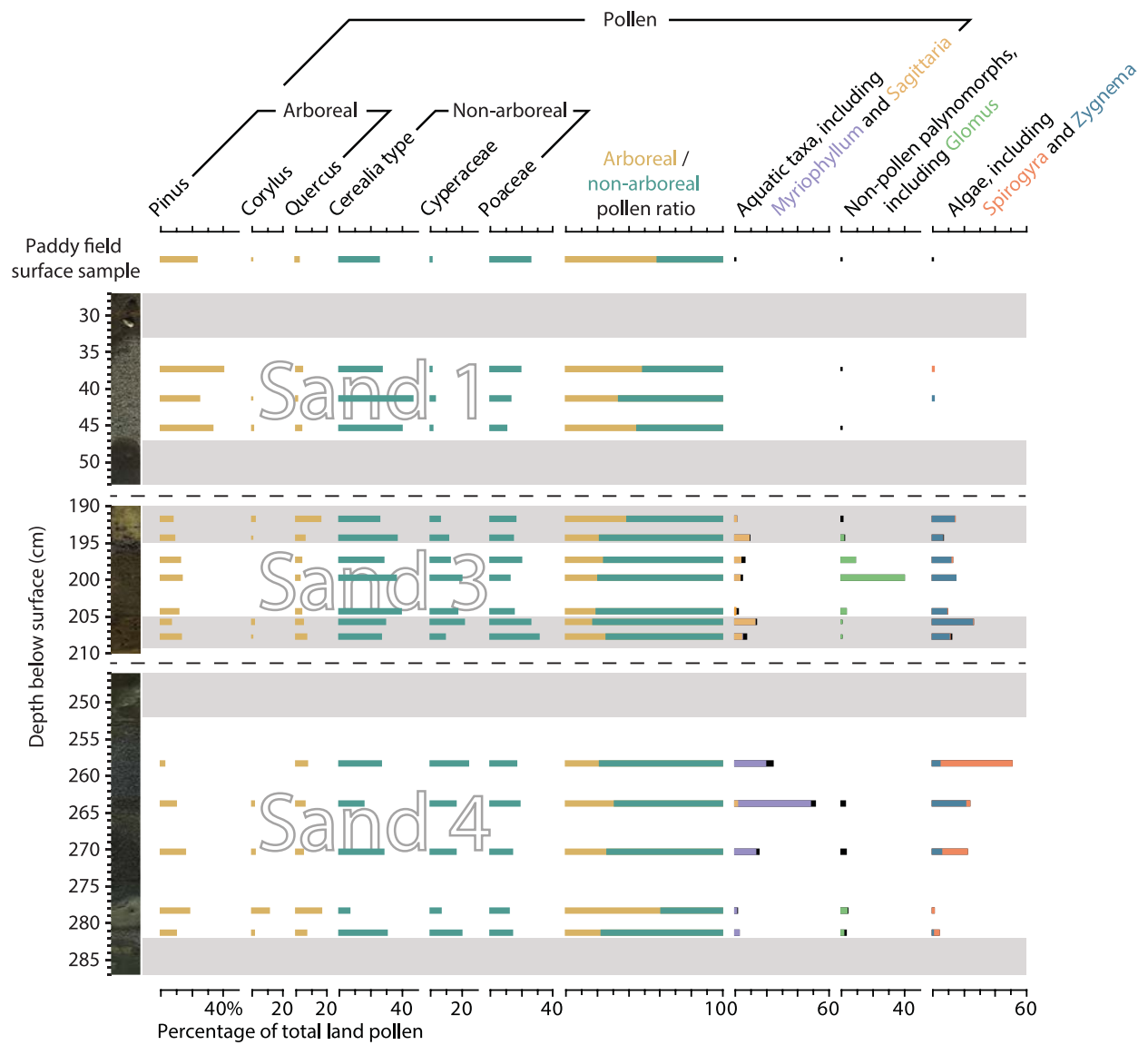

Figure 5. Summary of pollen, non-pollen palynomorphs and algae (species exceeding $10 \%$ in one or more sample) from Sands I, 3 and 4, the organic muds found immediately above and below Sand 3 and the paddy field surface sample. Sands I and 4 sampled in core JSH3/F; Sand 3 sampled in core JSH3/O. Relative abundances expressed as the percentage of the total land pollen sum.

five non-pollen palynomorphs and five green algal taxa. None of the taxa encountered are indicative of marine environments.

Sand 4 features Cyperaceae and grasses (Poaceae and Cerealiatype), with elevated arboreal pollen percentages (mainly Pinus, Corylus and Quercus) found particularly in the large mud clast. The middle and upper sand subunits of Sand 4, along with the internal silt drape, display elevated abundances of aquatic taxa, particularly Myriophyllum, and algae, including Spirogyra and Zygnema. In Sand 3, Pinus and Cyperaceae are found alongside cultivated and wild varieties of grass. Spores of the mycorrhizal fungus Glomus peak in abundance in this layer, while aquatic taxa, particularly Sagittaria, and algae, principally Zygnema, are also encountered at low abundances. Sand 1 contains abundant arboreal and non-arboreal pollen, including Pinus and grasses, but few aquatic taxa, non-pollen palynomorphs or algae.

The fine-grained sediment accumulation, typified by the organic silt units above and below Sand 3 and the sample from the contemporary paddy field surface, displays similar pollen assemblages to the sand layers. The silt layers in core JSH3/F contain Pinus, Cyperaceae and grass pollen, alongside occasional aquatic taxa, Zygnema and rare non-pollen palynomorphs. The surface sample contains Cryptomeria, Pinus, Cyperaceae and grass pollen; however, aquatic taxa, non-pollen palynomorphs and algae are rare, with Myriophyllum, Sagittaria, Glomus, Spirogyra and Zygnema absent.

\section{Chronology}

A Bayesian age model incorporating 11 of the 12 radiocarbon ages from macrofossil samples constrains the timing of the deposition of each of the four sand layers (Figure 6a, Table 1). We do not include the AIO radiocarbon dates in age model development because of highly variable offsets between paired macrofossil and AIO dates (Figure 6a). We also reject the radiocarbon dates from bulk samples, as these are inconsistently between 100 and 600 years older than macrofossil dates from the same stratigraphic context. The inconsistent bias towards older ages associated with the use of bulk samples is well-established (Nakamura et al., 2012, 2016; Törnqvist et al., 1992). Radiocarbon ages deduced from AIO fractions are also predominantly older than macrofossil dates as well as compound specific radiocarbon ages from the same horizons, depending on the residence time of carbon in the hinterlands (e.g. Ishiwa et al., 2016; Yokoyama et al., 2016). Finally, we do not incorporate one macrofossil sample because of its placement within a mud clast in Sand 4.

The radiocarbon age model constrains the timing of the emplacement of Sand 4 to 1154-1378 CE, Sand 3 to 1491-1610 CE, Sand 2 to $1601-1831 \mathrm{CE}$ and Sand 1 to $1730-1950$ CE. Profiles of ${ }^{210} \mathrm{~Pb}_{\mathrm{xs}}$ and ${ }^{137} \mathrm{Cs}$ provide further information on the depositional age of Sand 1 (Figure 6b). The CFCS model indicates a mean sedimentation rate of $0.54 \pm 0.10 \mathrm{~cm} \mathrm{yr}^{-1}$; extrapolation of this rate suggests a depositional age for Sand 1 of 1942-1964. The appearance of detectable levels of ${ }^{137} \mathrm{Cs}$ just below Sand 1 corroborates this estimate; the onset of ${ }^{137} \mathrm{Cs}$ in the environment occurs around 1950 (Figure 6b).

\section{Discussion}

Previous studies established that the stratigraphic record at Shirasuka preserves evidence for extreme wave events and terrestrial mass movements (Fujiwara et al., 2006; Komatsubara et al., 2006, 2008). Komatsubara et al. (2008) encountered between one and seven sand layers in each of their 11 geoslicer locations, with only one geoslice profile featuring all seven layers. Here, we have 

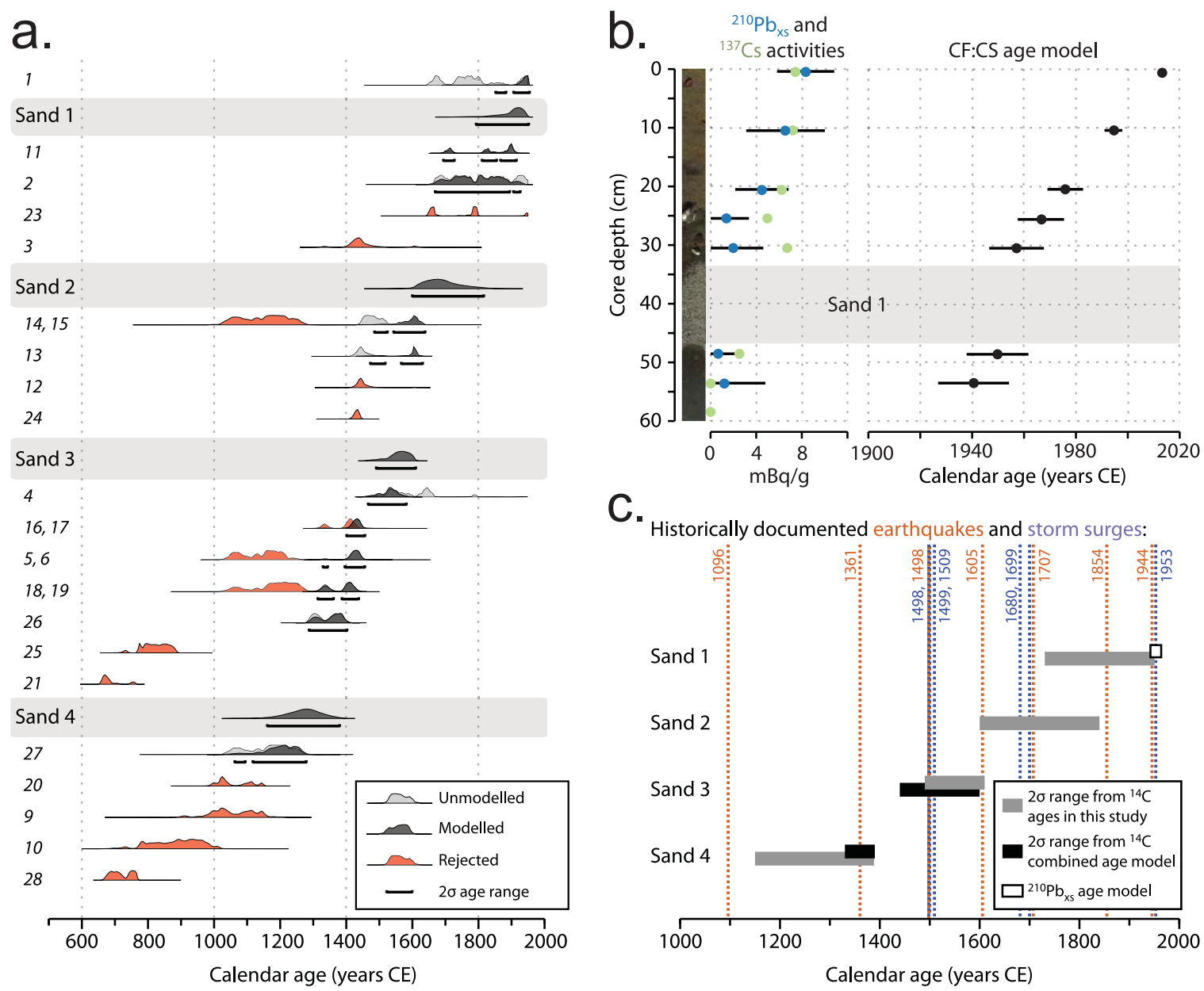

C.

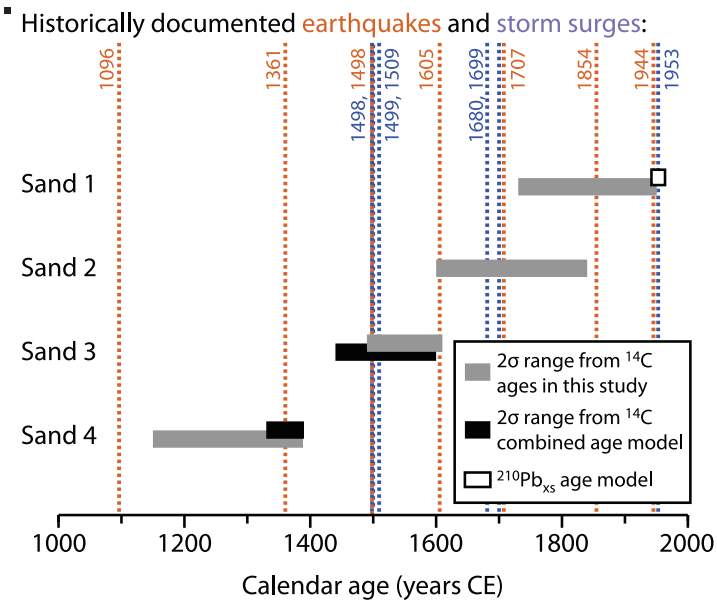

Figure 6. Timing of sand layer deposition at Shirasuka. (a) Radiocarbon Sequence model displaying prior and posterior probability density functions for samples reported in Table I (italicised numbers refer to sample numbers). Paired AIO and macrofossil samples aligned to facilitate comparison. (b) Radionuclide activity profiles and CF:CS age model used to determine the age of Sand I in core JSH3/F. (c) Comparison of age ranges from panels (a) and (b) with age ranges from a combined age model incorporating radiocarbon dates from Komatsubara et al. (2008) (Supplementary Figure SI, available online) and historically documented earthquakes and storm surges along the eastern Nankai-Suruga megathrust.

described the presence of four abruptly emplaced sand layers in a series of cores located within 25 m of Komatsubara et al.'s (2008) most comprehensive core. Comparison of the relative positioning and depth of each of these sand layers suggests that our two lowermost sand layers, Sands 4 and 3, can be correlated with the two lowermost sand layers reported by the previous study. Sand 1 can similarly be correlated with the uppermost sand layer. Correlation of the thick Sand 2 is, however, problematic, with the equivalent interval in Komatsubara et al.'s (2008) geoslice profile SRL4 featuring at least four discrete sand layers deposited by extreme wave events. The substantial thickness of Sand 2 and the chaotic structures revealed by X-ray CT scans raise the possibility that, in our cores, successive extreme wave events are overprinted and the layer relates to multiple events.

\section{Chronology and correlation with the historical record}

The ages of the four sand layers identified in the present study are consistent with historically documented earthquakes and extreme wave events occurring over the last $\sim 800$ years (Figure $6 \mathrm{c}$ ). The modelled age range for Sand 4, 1154-1378 CE, includes the 1361 Kōan earthquake and tsunami (also known by the Southern Court nengō (era name) of Shōhei). Komatsubara et al. (2008) interpreted this layer as resulting from a mass movement because of the finer grain-size distribution, presence of mica and landward thickening of the deposit, but did not discuss the timing of deposition. The following section provides further discussion of the origin of this layer. Reanalysis of radiocarbon ages from the earlier study suggests an age consistent with an earthquake in 1361 (see supplementary info. S1.6 in Garrett et al., 2016). A combined model incorporating radiocarbon data from Komatsubara et al. (2008) and from this study provides an age range of 1330-1390 CE (Supplementary Figure S1, available online), further corroborating our proposed correlation with an earthquake during this era. Single-grain infrared stimulated luminescence ages are also consistent with this hypothesis, with three ages constraining deposition to $1291 \pm 78,1364 \pm 72$ and $1390 \pm 64 \mathrm{CE}$ (Riedesel et al., in revision).

The modelled timing of the deposition of Sand 3, 1491-1610 CE, overlaps with the 1498 and 1605 tsunamis and storm surges in 1498, 1499 and 1509 (Figure 6c). Komatsubara et al. (2008) attributed the second oldest sand layer to the 1498 Meio tsunami, with reanalysis of their radiocarbon data suggesting an age range of 1390-1460 CE (Garrett et al., 2016). A combined age model incorporating radiocarbon dates from the previous and current studies provides a $2 \sigma$ range of $1442-1600$ CE (Supplementary Figure S1, available online), while luminescence approaches yield a $1 \sigma$ age of $1516 \pm 49$ (Riedesel et al., in revision). With extensive and well-documented evidence along the Enshu-nada coastline, including estimated wave heights of 6-8 $\mathrm{m}$ at the mouth of Lake Hamana (Hatori, 1975), the 1498 Meiō tsunami provides the most likely candidate for the origin of this sand layer.

The age model provides a long interval, 1601-1831 CE, for the deposition of Sand 2. This range overlaps with historically 
Table I. Radiocarbon dates from Shirasuka.

\begin{tabular}{|c|c|c|c|c|c|}
\hline Sample number & Laboratory code & Core & Depth $(\mathrm{cm})$ & Description & ${ }^{14} \mathrm{C}$ age $( \pm \mathrm{I} \sigma$ error) \\
\hline I & YAUT-016006 & $\mathrm{JSH} 3 / \mathrm{F}$ & $32 \pm 0.5$ & Plant macrofossils & $183 \pm 37$ \\
\hline 2 & YAUT-016007 & $\mathrm{JSH} 3 / \mathrm{F}$ & $47.5 \pm 0.5$ & Plant macrofossils & $144 \pm 42$ \\
\hline 3 & YAUT-02I 327 & $\mathrm{JSH} 3 / \mathrm{F}$ & $63.5 \pm 0.5$ & $\mathrm{AlO}$ fraction & $466 \pm 49^{a}$ \\
\hline 4 & YAUT-016012 & $\mathrm{JSH} 3 / \mathrm{F}$ & $237 \pm 0.5$ & Plant macrofossils & $279 \pm 35$ \\
\hline 5 & YAUT-016019 & $\mathrm{JSH} 3 / \mathrm{F}$ & $252 \pm 0.5$ & Plant macrofossils & $493 \pm 37$ \\
\hline 6 & YAUT-02। 333 & $\mathrm{JSH} 3 / \mathrm{F}$ & $252 \pm 0.5$ & AlO fraction & $882 \pm 39^{a}$ \\
\hline 7 & YAUT-02I 324 & $\mathrm{JSH} 3 / \mathrm{F}$ & $277 \pm 0.5$ & AIO fraction & $1285 \pm 26^{\mathrm{a}, \mathrm{b}}$ \\
\hline 8 & YAUT-02। 328 & $\mathrm{JSH} 3 / \mathrm{F}$ & $280.5 \pm 0.5$ & AIO fraction & $1030 \pm 59 \mathrm{a}, \mathrm{b}$ \\
\hline 9 & YAUT-02। 335 & $\mathrm{JSH} 3 / \mathrm{F}$ & $283 \pm 0.5$ & AlO fraction & $994 \pm 55^{\mathrm{a}}$ \\
\hline 10 & YAUT-02I 336 & $\mathrm{JSH} / \mathrm{F}$ & $304 \pm 1$ & AlO fraction & $1139 \pm 56^{a}$ \\
\hline 11 & YAUT-016008 & $\mathrm{JSH} 3 / \mathrm{O}$ & $69.5 \pm 0.5$ & Plant macrofossils & $4 \pm 37$ \\
\hline 12 & YAUT-02। 326 & $\mathrm{JSH} / \mathrm{O}$ & $129.5 \pm 0.5$ & AlO fraction & $443 \pm 29^{a}$ \\
\hline 13 & YAUT-016009 & $\mathrm{JSH} / \mathrm{O}$ & $177.75 \pm 0.75$ & Plant macrofossils & $44 I \pm 33$ \\
\hline 14 & YAUT-016010 & $\mathrm{JSH} 3 / \mathrm{O}$ & $194.5 \pm 0.5$ & Plant macrofossils & $385 \pm 35$ \\
\hline 15 & YAUT-02 I 334 & $\mathrm{JSH} 3 / \mathrm{O}$ & $194.5 \pm 0.5$ & AlO fraction & $869 \pm 68^{a}$ \\
\hline 16 & YAUT-0160II & $\mathrm{JSH} 3 / \mathrm{O}$ & $205.5 \pm 0.5$ & Plant macrofossils & $485 \pm 33$ \\
\hline 17 & YAUT-02। 322 & $\mathrm{JSH} 3 / \mathrm{O}$ & $205.5 \pm 0.5$ & AlO fraction & $536 \pm 29^{a}$ \\
\hline 18 & YAUT-0160I8 & $\mathrm{JSH} 3 / \mathrm{O}$ & $223.5 \pm 0.5$ & Plant macrofossils & $547 \pm 33$ \\
\hline 19 & YAUT-02। 338 & $\mathrm{JSH} 3 / \mathrm{O}$ & $223.5 \pm 0.5$ & AlO fraction & $833 \pm 6 \mathrm{I}^{\mathrm{a}}$ \\
\hline 20 & YAUT-02I 329 & $\mathrm{JSH} 3 / \mathrm{O}$ & $314 \pm 0.5$ & AlO fraction & $992 \pm 31^{a}$ \\
\hline 21 & YAUT-024I06 & JSHI/O & $186 \pm 1$ & Bulk & $1325 \pm 20 c$ \\
\hline 22 & YAUT-024107 & $\mathrm{JSHI} / \mathrm{O}$ & $220.5 \pm 0.5$ & Wood fragments & $359 \pm 20^{b}$ \\
\hline 23 & YAUT-024I04 & $\mathrm{JSHIb} / \mathrm{F}$ & $56.5 \pm 0.5$ & AlO fraction & $223 \pm 21^{a}$ \\
\hline 24 & YAUT-024I05 & $\mathrm{JSHIb} / \mathrm{F}$ & $159.5 \pm 0.5$ & AlO fraction & $480 \pm 19^{a}$ \\
\hline 25 & YAUT-024109 & $\mathrm{JSHIb} / \mathrm{F}$ & $254 \pm 1$ & Bulk & $1205 \pm 20^{c}$ \\
\hline 26 & YAUT-0227I 7 & $\mathrm{JSHIb} / \mathrm{F}$ & $262.5 \pm 2.5$ & Wood fragments & $639 \pm 37$ \\
\hline 27 & YAUT-022718 & $\mathrm{JSHIb} / \mathrm{F}$ & $314 \pm 1$ & Wood fragments & $863 \pm 58$ \\
\hline 28 & YAUT-024I I I & $\mathrm{JSHIb} / \mathrm{F}$ & $334 \pm 1$ & Bulk & $1284 \pm\left. 2\right|^{c}$ \\
\hline
\end{tabular}

AIO: acid insoluble organic

aRejected because of variable offsets between paired macrofossil and AIO dates.

bRejected because of uncertain stratigraphic context (mud clast).

cRejected because of variable offsets between bulk and macrofossil dates from the same stratigraphic context.

documented tsunamis in 1605 and 1707 and storm surges in 1680 and 1699 (Figure 6c). The 1854 Ansei-Tōkai tsunami also lies just outside the $2 \sigma$ range. The long interval may partly relate to a plateau in the radiocarbon calibration curve, but could also support our suggestion of the deposition and overprinting of multiple sand layers over an extended period of time. Luminescence ages support this interpretation, with the age of the lower part of the deposit consistent with the 1605 Keichō tsunami and the upper part dating to the mid to late 18th century (Riedesel et al., in revision). Komatsubara et al. (2008) identified four sand layers within this interval, attributing them to tsunamis in 1605, 1707 and 1854 and either the 1680 or 1699 storm surge.

The age range for the uppermost sand layer, constrained to 1942-1964 CE by radiocarbon and radionuclide approaches, overlaps with the 1944 Showa-Tōnankai earthquake and the storm surge accompanying Typhoon Tess in 1953 (Figure 6c). Luminescence ages provide further corroboration, dating Sand 1 to $1948 \pm 8(1 \sigma)$ (Riedesel et al., in revision). Komatsubara et al. (2008) suggested a terrestrial origin for this sand layer and did not discuss the timing of deposition.

\section{Depositional mechanisms}

Komatsubara et al. (2008) interpreted the lowermost sand layer as being derived from the terrace cliff based on its finer grain-size distribution, mica content and landward thickening. In our study, the sedimentary structures identified in Sand 4 support the alternative hypothesis of tsunami inundation following the $1361 \mathrm{CE}$ Kōan earthquake. Sand 4 exhibits numerous features frequently linked with tsunami deposition, including abrupt contacts, rip-up clasts, inverse and normally graded beds and an internal mud drape, suggesting the repeated occurrence of waning and reactivation of sediment flows. Furthermore, the grain-size distributions are similar to both Sands 3 and 2 and the modern upper beach sample. The presence of well-preserved marine and brackish diatoms, found at higher percentages in Sand 4 than in any other layer, supports a marine contribution. The presence of freshwater diatoms, pollen from submerged aquatic plants and aquatic green algal taxa indicates sediment was also entrained from freshwater environments. The findings of Komatsubara et al. (2008) and of this study are not mutually exclusive; tsunamis may be accompanied by mass movements triggered by intense shaking. Cisternas et al. (2017) provide an example of this coincidence from south central Chile, highlighting spatial variability in the thickness and presence/absence of both tsunami and debris flow deposits resulting from the same earthquake. At Shirasuka, intense shaking may have destabilised the steep slopes above the lowland, with tsunami waves, particularly return flows, redistributing mass movement deposits.

The origin of Sand 3 cannot be identified from the sedimentology and microfossil assemblages in the absence of the chronological and historical information discussed in the previous section. Some notable sedimentary features are present, including abrupt contacts, multiple beds, entrained vegetation and rip-up clasts. While these structures may be consistent with deposition during tsunamis, they may also characterise storm surge deposits (Engel and Brückner, 2011; Morton et al., 2007; Shanmugam, 2012). Sand 3 displays grain-size distributions most closely reflecting the modern samples from the upper beach and lower dune. Grain-size data suggest beach and dune environments 

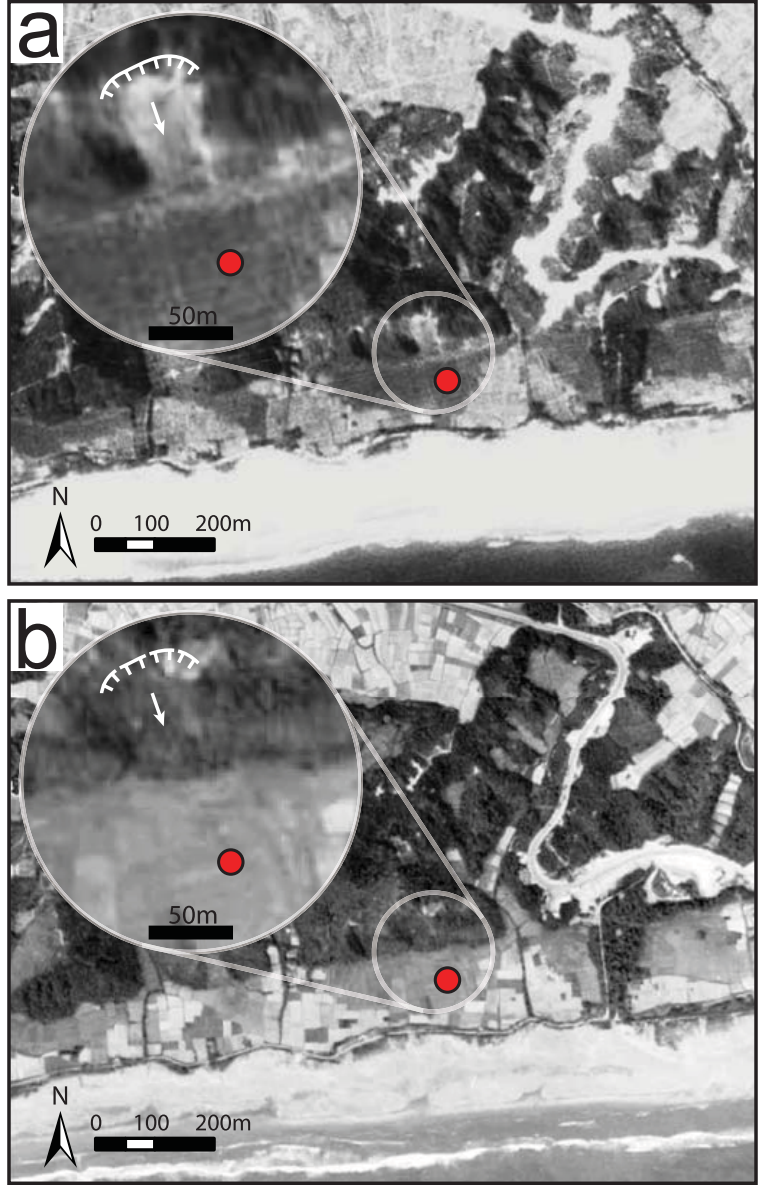

Figure 7. Orthorectified aerial photographs of the Shirasuka lowlands from (a) August 1947, 2.5 years after the December 1944 Showa-Tōnankai earthquake and (b) May 1959, 14.5 years after the 1944 earthquake. Circles indicate the location of the cores used in this study and white hachured lines indicate the active scarp. Aerial photographs provided by the Geographical Survey Institute (http:// mapps.gsi.go.jp)

contributed significantly to sediments deposited by the 2011 Tōhoku tsunami in north-east Japan (Nakamura et al., 2012; Szczuciński et al., 2012); however, a more comprehensive set of modern samples including low intertidal and subtidal sediments would be necessary to further assess the provenance of this sand layer. While Sand 3 may have been derived from beach and dune environments, diatom and palynomorph assemblages suggest a predominantly freshwater source. As none of the contemporary beach or dune samples yielded any diatoms, we suggest the 1498 CE Meiō tsunami may have eroded material from a range of saline and freshwater environments. Tsunami waves may have entrained and mixed diatom-poor beach or dune sand with freshwater marsh sediments rich in diatoms, aquatic pollen and green algae. While the presence of marine or brackish diatoms is often a strong indicator of a marine source (e.g. Dawson et al., 1996; Hemphill-Haley, 1996; Nanayama et al., 2007), freshwater assemblages characterise the 2011 Tōhoku tsunami deposit in many areas, indicating dilution of marine species by abundant freshwater diatoms (Szczuciński et al., 2012; Takashimizu et al., 2012; Tanigawa et al., 2016). Freshwater assemblages similarly characterise probable late-Holocene tsunami deposits at sites in Alaska and Chile (Cisternas et al., 2017; Nelson et al., 2015). The presence of freshwater aquatic pollen, non-pollen palynomorphs and algae in Sand 3 may also result from this mixing of sediment sources. The increased abundance of Glomus spores indicates redistribution of sediment from terrestrial environments. The presence of this mycorrhizal fungus may be associated with erosion of soils (Silva-Sánchez et al., 2014; Van Geel et al., 1989) and has been employed as a marker of erosion in coastal marsh environments (Kouli, 2012).

As discussed in relation to Sand 3, grain-size distributions in Sand 2 most closely resemble the modern beach and dune samples, with the presence freshwater diatom assemblages explained by mixing of different sediment sources. We suggest overprinting of multiple extreme wave event deposits during the 17th and 18th centuries CE could explain the substantial thickness of Sand 2 and the difficulties in correlating this interval with the four sand layers identified by Komatsubara et al. (2008). The thickness of the deposit in our cores, the lack of grading or identifiable characteristic sedimentary structures and the long age range provided by age modelling suggest the possibility of post-depositional modification and homogenisation in this particular location. The site has been intermittently used for rice cultivation, and repeated ploughing and redistribution or removal of finer grained sediment layers for agricultural purposes could have contributed to the lack of distinct layering observed in the earlier study. Successive extreme wave events may also have resulted in local erosion of the intervening finer grained layers and mixing and redistribution of sandy units.

Komatsubara et al. (2008) identified a terrestrial origin for the uppermost sand layer based on the presence of mica, which dominates the terrace sediment matrix but is not found in modern foreshore samples. Our results agree with the terrestrial source of this layer. Sedimentation associated with the 1944 Showa-Tonnankai tsunami can be ruled out as it did not overtop the dune ridge; Watanabe (1998) reported wave heights of $0.9 \mathrm{~m}$ at the entrance to Lake Hamana. A landslide or debris flow originating from the midPleistocene terrace appears the most likely origin; the timing and cause of this mass movement is discussed further in the following section. Sand 1 is similar to the other sand layers, with a comparable thickness, a marginally coarser grain-size distribution and an abrupt lower contact. The deposit is inversely graded; while this has been recorded in deposits from both storm surges (e.g. Williams, 2009) and tsunamis (e.g. Naruse et al., 2010), normal grading is more commonly reported during these events (Morton et al., 2007). Optically stimulated luminescence overdispersion values of single-grain feldspars are higher than expected, potentially indicating a different transport mechanism than that associated with the other sand layers (Riedesel et al., in revision). The prevalence of freshwater diatom species in Sand 1, as seen in the underlying sand layers, again points towards redistribution of material from terrestrial environments. Nevertheless, the near absence of aquatic pollen, non-pollen palynomorphs and algae suggests a lack of erosion of freshwater marshes, in contrast to the other sand layers.

\section{Earthquake-triggered mass movements?}

Sand 1, constrained to 1942 to 1964 CE by radionuclide dating, is consistent with a mass movement from the landward terrace. Shaking during the 1944 earthquake or intense rainfall associated with the 1953 typhoon provide two plausible triggers. Aerial photographs from 1947 confirm the occurrence of a mass movement, with a fresh scarp and exposed bare soil visible on the steep terrace slope above the coring location (Figure 7a). The slope rises at an angle of more than $30^{\circ}$ to a height of $45 \mathrm{~m}$ above the coastal lowland (Figure 1f). The date of this photograph discounts the typhoon as the trigger, but is consistent with the timing of the Showa-Tōnankai earthquake. The high rate of vegetation growth, highlighted by revegetation of the slope by 1959 (Figure 7b), further suggests the mass movement occurred shortly before 1947.

While secondary ground failures may provide evidence of seismic shaking (Keefer, 1984, 2002), field investigations along the Nankai-Suruga megathrust have chiefly focussed on liquefaction features (Sangawa, 2009, 2013), or turbidites in marine 
and lacustrine settings (Inouchi et al., 1996; Iwai et al., 2004). Hatori (1975) suggested landslides accompanied the 1498 earthquake, and Usami (2003) listed landslides associated with the 1361, 1707 and 1854 earthquakes; however, subaerial mass movement deposits have not received extensive study in this region. Nevertheless, our findings suggest they could provide a valuable and complementary coastal palaeoseismic approach. Failures of uplifted marine terraces have informed understanding of the timing of large to great earthquakes in Papua New Guinea (Ota et al., 1997) and Chile (Cisternas et al., 2017), while mass movements have been more widely used for palaeoseismic investigations in non-coastal settings (Gutiérrez et al., 2008; Jibson, 1996; Mitchell et al., 2007). Extensive uplifted marine terraces located above coastal lowland depocentres along the southern and eastern coasts of Japan (Koike and Machida, 2001) further indicate that this could be a viable approach in Japanese subduction zone settings. As with turbidite-based palaeoseismic investigations, the potential for mass movements triggered by typhoons rather than earthquakes would need to be assessed (cf. Shirai et al., 2010). Analysis of mass movement inventories associated with recent historical earthquakes, further development of inventories of typhoon triggered mass movements (e.g. Saito et al., 2010) and regional correlation of coeval mass movement deposits may provide helpful steps towards developing this approach.

\section{Implications for historical rupture zones}

Komatsubara et al. (2008) correlated sand layers at Shirasuka with tsunami inundation in 1498, 1605, 1707 and 1854, alongside storm surge inundation in the late 17 th century. Here, we have additionally established the presence of sand layers consistent with tsunami inundation in 1361 and a seismically triggered mass movement in 1944.

Evidence from historical records and liquefaction features at archaeological sites suggests that the Kōan earthquake ruptured the Nankai region, the western half of the Nankai-Suruga megathrust, on 26 July 1361 (Ishibashi and Satake, 1998; Sangawa, 2013). Ishibashi (2004) and Seno (2012) raised the possibility of an eastwards extension of coseismic slip into the Tonankai region, based on historical and geoarchaeological data. Ishibashi and Satake (1998) and Ishibashi (2014) provided an alternative hypothesis, suggesting a separate earthquake in the Tōnankai region in the early morning of 24 July, 2 days before the rupture of the Nankai region. While documentary evidence supports intense shaking around Kyoto and the Kii Peninsula at this time, there is no record of a concurrent tsunami along the Pacific coast. Garrett et al. (2016) summarised geological records and suggested that the wide distribution of possible evidence supported a rupture incorporating the Nankai, Tōnankai and Tōkai regions. Nevertheless, the paucity of well-constrained chronologies and unequivocal evidence for tsunami deposition limited the confidence of this assertion. Furthermore, either the eastwards extension of coseismic slip on 26 July 1361 or the occurrence of a separate rupture of the Tōnankai region on 24 July 1361 could explain the mapped distribution of geological evidence. In the absence of well-dated and comprehensively reported evidence from other palaeoseismic sites, Sand 4 at Shirasuka currently provides the most compelling evidence for tsunami inundation in 1361 from any site along the Nankai-Suruga megathrust. This finding is consistent with either a single larger rupture of both the Nankai and Tōnankai regions or two smaller ruptures separated by 2 days. While the identification of tsunami deposits at Shirasuka does not necessarily imply a rupture of the adjacent region of the megathrust, more recent ruptures of just the Nankai region in 1854 (Ansei-Nankai) and 1946 (Showa-Nankai) did not generate significant wave heights along the coastlines of the Tōnankai region (Watanabe, 1998). Intense shaking implied by the possible coeval occurrence of a mass movement at Shirasuka (Komatsubara et al., 2008) further supports the inferred rupture of the Tōnankai region in 1361. With the 1361 Kōan earthquake proposed as the start of a supercycle that culminated with the 1707 Hōei earthquake (Furumura et al., 2011; Garrett et al., 2016; Seno, 2012), further efforts to constrain the rupture zone or zones are clearly warranted.

The correlation of Sand 3 with the 1498 CE Meiō tsunami reaffirms the findings of Komatsubara et al. (2008). Proposed evidence for this tsunami is widespread in the Tonankai region, including at Shijima (Fujino et al., 2008; Komatsubara and Okamura, 2007) and along the Enshu-nada coastline at Arai (Fujiwara et al., 2013), Lake Hamana (Honda and Kashima, 1997) and Nagaya Moto-Yashiki (Takada et al., 2002). Historical, archaeological and geological records are in agreement, suggesting a rupture of the Tōnankai region (Garrett et al., 2016; Ishibashi, 2004; Sangawa, 2009; Seno, 2012). Liquefaction features at archaeological sites may imply a second earthquake or a westwards extension of the $1498 \mathrm{CE}$ rupture zone into the Nankai region (Sangawa, 2009).

The difficulties encountered in attributing Sand 2 to particular extreme wave events prevent further analysis based on the findings presented here. If the site does record tsunami inundation in 1605, 1707 and 1854, as asserted by Komatsubara et al. (2008), this is in keeping with current understanding of the rupture zones of these earthquakes (Garrett et al., 2016; Ishibashi, 2004; Satake, 2015; Seno, 2012). The substantial differences in sand layer thickness between our work and the previous study at Shirasuka reinforce the high degree of variability in the stratigraphy and sedimentology of tsunami deposits on a very fine spatial scale. Furthermore, the overprinting of multiple extreme wave events highlights the potential for geological records to underestimate the frequency and overestimate the recurrence interval between events.

While inversion of geodetic and tsunami wave form data confidently places the 1944 Showa-Tōnankai rupture zone in the Tōnankai region (Ando, 1975; Baba and Cummins, 2005; Tanioka and Satake, 2001), sedimentary evidence for this earthquake is limited. Intense shaking may be recorded by turbidite and mud breccia deposits from the Kumano Trough (Sakaguchi et al., 2011; Shirai et al., 2010) and liquefaction features at Tadokoro (Sangawa, 2009). Evidence for a mass movement at Shirasuka may provide a rare terrestrial record of seismic shaking in 1944.

\section{Conclusion}

Geological investigations provide an independent approach to test hypotheses concerning past Nankai-Suruga megathrust earthquakes and tsunamis derived from historical records. This study assesses abruptly emplaced sand layers on the coastal lowlands at Shirasuka, using a rigorous multi-proxy approach to assess, reinterpret and build on the earlier work of Fujiwara et al. (2006) and Komatsubara et al. (2006, 2008). Reporting the results of new stratigraphic investigations, X-ray CT scanning and analyses of particle size, diatoms, pollen and non-pollen palynomorphs, we have identified four sand layers that reflect not only inundation during tsunamis or typhoon-driven storm surges but also the occurrence of a terrestrial mass movement. The oldest sand layer is consistent with the $1361 \mathrm{CE}$ Kōan tsunami; the presence of this deposit and possible evidence for coeval shaking support the latest interpretation of the Kōan earthquake constituting a full-length rupture equivalent to the $1707 \mathrm{CE}$ Hōei earthquake (Furumura et al., 2011; Garrett et al., 2016; Seno et al., 2012). We cannot discount an alternative hypothesis of two closely spaced ruptures of the Nankai and Tōnankai regions (Ishibashi, 2014; Ishibashi 
and Satake, 1998), but emphasise that either hypothesis implies slip in the Tōnankai region at this time.

With Bayesian age models incorporating 11 new radiocarbon dates, we verify evidence for inundation during the $1498 \mathrm{CE}$ Meiō tsunami deposit. While Komatsubara et al. (2008) identified four discrete sand layers associated with tsunamis in 1605, 1707 and $1854 \mathrm{CE}$ and a storm surge in 1680 or 1699 , we encountered a single $50-\mathrm{cm}$-thick sand at our coring locations. The probable overprinting of evidence previously attributed to multiple extreme wave events highlights both the high degree of lateral variability in the deposits and the potential for geological records to underestimate the frequency of tsunami occurrence.

By combining radionuclide dating with analysis of aerial photographs, we have demonstrated that the 1944 CE ShowaTōnankai earthquake is the likely trigger for the mass movement responsible for depositing the youngest sand layer. Previously identified as of terrestrial origin (Komatsubara et al., 2008), we suggest this deposit constitutes a rare geological record of the most recent great earthquake in the region. The occurrence of earthquake-triggered failures of uplifted marine terraces supports the development of terrestrial mass movement deposits as a complementary palaeoseismic approach in this and other regions.

\section{Acknowledgements}

We thank landowners in the study area for allowing us access to their land; Martin Seeliger, Stephen Obrochta, Gen Nagano, Laura Lamair and Eisuke Ono for their help in the field; Thomas Govaerts for preparing samples; Maarten Van Daele for providing his CT scanning expertise; and Yoshiki Sato, Yuki Sawai and Tomonori Naya for helpful discussions over diatom taxonomy. This paper is a contribution to IGCP project 639 and the INQUA focus group 'Late Quaternary records of coastal inundation due to earth surface deformation, tsunamis, and storms'. The list of members of the QuakeRecNankai team is available from http:// www.quakerecnankai.ugent.be/index.php?team.

\section{Funding}

This research was undertaken under the auspices of the QuakeRecNankai project, funded by the Belgian Science Policy Office (BELSPO BRAIN-be BR/121/A2).

\section{ORCID iD}

Ed Garrett (D) https://orcid.org/0000-0001-9985-0651. Jan Walstra (D) https://orcid.org/0000-0001-9721-124X. Marc De Batist (D) https://orcid.org/0000-0002-1625-2080.

\section{References}

Ando M (1975) Source mechanisms and tectonic significance of historical earthquakes along the Nankai Trough, Japan. Tectonophysics 27(2): 119-140.

Appleby PG (1998) Dating recent sediments by $210 \mathrm{~Pb}$ : problems and solutions. In: Ilus E (ed.) Dating of sediments and determination rate. Vol STUK-A145. Helsinki: STUK, pp. 7-24.

Appleby PG and Oldfield F (1978) The calculation of lead-210 dates assuming a constant rate of supply of unsupported $210 \mathrm{~Pb}$ to the sediment. Catena 5 : 1-8.

Baba T and Cummins PR (2005) Contiguous rupture areas of two Nankai Trough earthquakes revealed by high-resolution tsunami waveform inversion. Geophysical Research Letters 32: L08305.

Baba T, Tanioka Y, Cummins PR et al. (2002) The slip distribution of the 1946 Nankai earthquake estimated from tsunami inversion using a new plate model. Physics of the Earth and Planetary Interiors 132(1): 59-73.

Beug HJ (2004) Leitfaden der Pollenbestimmung für Mitteleuropa und angrenzende Gebiete. Munich: Verlag Friedrich Pfeil.
Blott SJ and Pye K (2001) Technical communication GRADISTAT: A grain size distribution and statistics package for the analysis of unconsolidated sediments. Earth Surface Processes and Landforms 26(11): 1237-1248.

Bondevik S, Svendsen JI and Mangerud J (1998) Distinction between the Storegga tsunami and the Holocene marine transgression in coastal basin deposits of western Norway. Journal of Quaternary Science 13(6): 529-537.

Bronk Ramsey C (1995) Radiocarbon calibration and analysis of stratigraphy; the OxCal program. Radiocarbon 37(2): 425-430.

Bronk Ramsey C (2009) Bayesian analysis of radiocarbon dates. Radiocarbon 51(1): 337-360.

Central Disaster Management Council (2012) Final Report Toward the Reconstruction for Sound and Unwavering Japan. Tokyo: Japanese Cabinet Office.

Chiba T, Sugihara S, Matsushima Y et al. (2016) Reconstruction of Holocene relative sea-level change and residual uplift in the Lake Inba area, Japan. Palaeogeography, Palaeoclimatology, Palaeoecology 441: 982-996.

Cisternas M, Garrett E, Wesson RL et al. (2017) Unusual geologic evidence of coeval seismic shaking and tsunamis shows variability in earthquake size and recurrence in the area of the giant 1960 Chile earthquake. Marine Geology 385: 101-113.

Cuven S, Paris R, Falvard S et al. (2013) High-resolution analysis of a tsunami deposit: Case-study from the 1755 Lisbon tsunami in southwestern Spain. Marine Geology 337: 98-111.

Dawson S, Smith DE, Ruffman A et al. (1996) The diatom biostratigraphy of tsunami sediments: Examples from recent and middle Holocene events. Physics and Chemistry of the Earth 21(1): 87-92.

Demske D, Tarasov PE and Nakagawa T (2013) Atlas of pollen, spores and further non-pollen palynomorphs recorded in the glacial-interglacial late Quaternary sediments of Lake Suigetsu, central Japan. Quaternary International 290: 164-238.

Dura T, Hemphill-Haley E, Sawai Y et al. (2016) The application of diatoms to reconstruct the history of subduction zone earthquakes and tsunamis. Earth-Science Reviews 152: 181-197.

Engel M and Brückner H (2011) The identification of palaeotsunami deposits - A major challenge in coastal sedimentary research. Coastline Reports 17: 65-80.

Fujino S, Komatsubara J, Shishikura M et al. (2008) Preliminary results on paleotsunami study by hand coring in Shima Peninsula, Mie Prefecture, central Japan. Annual Report on Active Fault and Paleoearthquake Researches 8: 255-265.

Fujiwara O, Komatsubara J, Takada K et al. (2006) Temporal development of a late-Holocene strand plain system in the Shirasuka area along western Shizuoka Prefecture on the Pacific coast of central Japan. Chigaku Zasshi 115(5): 569-581.

Fujiwara O, Ono E, Yata T et al. (2013) Assessing the impact of 1498 Meio earthquake and tsunami along the Enshu-nada coast, central Japan using coastal geology. Quaternary International 308: 4-12.

Furumura T, Imai K and Maeda T (2011) A revised tsunami source model for the 1707 Hoei earthquake and simulation of tsunami inundation of Ryujin Lake, Kyushu, Japan. Journal of Geophysical Research: Solid Earth (1978-2012) 116(B2): B02308.

Garrett E, Fujiwara O, Garrett P et al. (2016) A systematic review of geological evidence for Holocene earthquakes and tsunamis along the Nankai-Suruga Trough, Japan. Earth-Science Reviews 159: 337-357.

Garrett E, Shennan I, Watcham EP et al. (2013) Reconstructing paleoseismic deformation, 1: Modern analogues from the 1960 and 2010 Chilean great earthquakes. Quaternary Science Reviews 75: 11-21. 
Goff J, Pearce S, Nichol SL et al. (2010) Multi-proxy records of regionally-sourced tsunamis, New Zealand. Geomorphology 118: 369-382.

Goto K, Fujino S, Sugawara D et al. (2014) The current situation of tsunami geology under new policies for disaster countermeasures in Japan. Episodes 37(4): 258-264.

Grand Pre CA, Horton BP, Kelsey HM et al. (2012) Stratigraphic evidence for an early Holocene earthquake in Aceh, Indonesia. Quaternary Science Reviews 54: 142-151.

Gutiérrez F, Ortuño M, Lucha P et al. (2008) Late Quaternary episodic displacement on a sackung scarp in the central Spanish Pyrenees: Secondary paleoseismic evidence? Geodinamica Acta 21(4): 187-202.

Hartley B, Barber H and Carter J (1996) An Atlas of British Diatoms. Bristol: Biopress.

Hatori T (1975) Sources of large tsunamis generated in the Boso, Tōkai and Nankai regions in 1498 and 1605. Bulletin of the Earthquake Research Institute of the University of Tokyo 50: 171-185.

Hemphill-Haley E (1993) Taxonomy of recent and fossil (Holocene) diatoms (Bacillariophyta) from northern Willapa Bay, Washington. US Geological Survey Open File Report: 93289: 1-151.

Hemphill-Haley E (1996) Diatoms as an aid in identifying lateHolocene tsunami deposits. The Holocene 6(4): 439-448.

Hippensteel SP and Martin RE (1999) Foraminifera as an indicator of overwash deposits, barrier island sediment supply, and barrier island evolution: Folly Island, South Carolina. Palaeogeography, Palaeoclimatology, Palaeoecology 149(1): 115-125.

Hirabayashi S, Yokoyama Y, Suzuki A et al. (2017) Multidecadal oceanographic changes in the western Pacific detected through high-resolution bomb-derived radiocarbon measurements on corals. Geochemistry, Geophysics, Geosystems. Epub ahead of print 19 April. DOI: 10.1002/2017GC006854.

Hirose F, Nakajima J and Hasegawa A (2008) Three-dimensional seismic velocity structure and configuration of the Philippine Sea slab in southwestern Japan estimated by double-difference tomography. Journal of Geophysical Research: Solid Earth 1978-2012 113(B9): B09315.

Honda S and Kashima K (1997) Paleo-environmental changes during the last 1,000 years from a lake deposit at Lake Hamana, central Japan. Laguna 4: 69-76.

Ikehara K, Irino T, Usami K et al. (2014) Possible submarine tsunami deposits on the outer shelf of Sendai Bay, Japan resulting from the 2011 earthquake and tsunami off the Pacific coast of Tohoku. Marine Geology 358: 120-127.

Inouchi Y, Kinugasa Y, Kumon F et al. (1996) Turbidites as records of intense palaeoearthquakes in Lake Biwa, Japan. Sedimentary Geology 104(1): 117-125.

Ishibashi K (2004) Status of historical seismology in Japan. Annals of Geophysics 47(2-3): 339-368.

Ishibashi K (2014) Nankai Trough Great Earthquake - History, Science and Society. Tokyo: Iwanami Shoten, $205 \mathrm{pp}$.

Ishibashi K and Satake K (1998) Problems on forecasting great earthquakes in the subduction zones around Japan by means of paleoseismology. Zisin 50: 1-21.

Ishiwa T, Yokoyama Y, Miyairi Y et al. (2016) Sedimentary environmental change induced from late Quaternary sea-level change in the Bonaparte Gulf, northwestern Australia. Geoscience Letters 3: 33.

Isomi H and Inoue M (1969) Geology of the Hamamatsu District (Geological Map Quadrangle Series 1:50,000, map sheet 11-059). Tsukuba: Geological Survey of Japan.

Iwai M, Fujiwara O, Momma $\mathrm{H}$ et al. (2004) Holocene seismoturbidites from the Tosabae Trough a landward slope basin of Nankai Trough off Muroto: Core KR9750P1. Memoirs of the Geological Society of Japan 58: 137-152.
Japan Meteorological Agency (2017) Typhoon statistics. Available at: http://www.data.jma.go.jp/fcd/yoho/typhoon/statistics/ index.html (accessed 31 May 2017).

Jibson RW (1996) Use of landslides for paleoseismic analysis. Engineering Geology 43(4): 291-323.

Keefer DK (2002) Investigating landslides caused by earthquakes - A historical review. Surveys in Geophysics 23: 473-510.

Keefer DK (1984) Landslides caused by earthquakes. The Geological Society of America Bulletin 95: 406-421.

Kitamura A (2016) Examination of the largest-possible tsunamis (Level 2) generated along the Nankai and Suruga troughs during the past 4000 years based on studies of tsunami deposits from the 2011 Tohoku-oki tsunami. Progress in Earth and Planetary Science 3: 12.

Kobayasi H (2006) Atlas of Japanese Diatoms Based on Electron Microscopy. Tokyo: Uchida Rokakuho.

Koike K and Machida H (2001) Atlas of Quaternary Marine Terraces in the Japanese Islands. Tokyo: University of Tokyo Press.

Komatsubara J and Okamura Y (2007) Preliminary research of tsunami deposits in the Shijima Lowland, Shima Peninsula, central Japan. Annual Report on Active Fault and Paleoearthquake Researches 7: 209-217.

Komatsubara J, Fujiwara O, Takada K et al. (2006) Historical tsunamis and storms recorded in a coastal lowland deposit, along the Nankai Trough, southwestern Japan. Annual Report on Active Fault and Paleoearthquake Researches 6: 107-122.

Komatsubara J, Fujiwara O, Takada K et al. (2008) Historical tsunamis and storms recorded in a coastal lowland, Shizuoka Prefecture, along the Pacific Coast of Japan. Sedimentology 55(6): 1703-1716.

Kouli K (2012) Vegetation development and human activities in Attiki (SE Greece) during the last 5,000 years. Vegetation History and Archaeobotany 21(4-5): 267-278.

Leica Geosystems (2002a) Imagine Orthobase User's Guide. Atlanta, GA: Leica Geosystems GIS and Mapping Division, $254 \mathrm{pp}$.

Leica Geosystems (2002b) Stereo Analyst User's Guide. Atlanta, GA: Leica Geosystems GIS and Mapping Division, 484 pp.

Lienkaemper JJ and Ramsey CB (2009) OxCal: Versatile tool for developing paleoearthquake chronologies - A primer. Seismological Research Letters 80(3): 431-434.

Loveless JP and Meade BJ (2010) Geodetic imaging of plate motions, slip rates, and partitioning of deformation in Japan. Journal of Geophysical Research: Solid Earth 115(B2): B09315.

Loveless JP and Meade BJ (2016) Two decades of spatiotemporal variations in subduction zone coupling offshore Japan. Earth and Planetary Science Letters 436: 19-30.

Lowe RL (1974) Environmental Requirements and Pollution Tolerance of Freshwater Diatoms. Cincinnati, OH: US Environmental Protection Agency.

May SM, Falvard S, Norpoth M et al. (2016) A mid-Holocene candidate tsunami deposit from the NW Cape (Western Australia). Sedimentary Geology 332: 40-50.

Mazada Y (1984) Year-to-year change in water exchange characteristics in a semi-enclosed bay, Lake Hamana. Journal of the Oceanographical Society of Japan 40(3): 199-206.

Mazzotti S, Le Pichon X, Henry P et al. (2000) Full interseismic locking of the Nankai and Japan-west Kurile subduction zones: An analysis of uniform elastic strain accumulation in Japan constrained by permanent GPS. Journal of Geophysical Research: Solid Earth 105(B6): 13159-13177.

Mitchell WA, McSaveney MJ, Zondervan A et al. (2007) The Keylong Serai rock avalanche, NW Indian Himalaya: Geomorphology and palaeoseismic implications. Landslides 4(3): 245-254. 
Moore P, Webb J and Collinson M (1991) Pollen Analysis Oxford: Blackwell.

Morton RA, Gelfenbaum G and Jaffe BE (2007) Physical criteria for distinguishing sandy tsunami and storm deposits during modern examples. Sedimentary Geology 200: 184-207.

Murray JW and Alve E (1999) Natural dissolution of modern shallow water benthic foraminifera: Taphonomic effects on the palaeoecological record. Palaeogeography, Palaeoclimatology, Palaeoecology 146(1): 195-209.

Mustari AS, Kato S and Aoki S (2012) Shoreline behaviour around the inlet of Imagire-Guchi. Presented at the 8th International Symposium on Lowland Technology, Bali, 11-13 September.

Nakajima J and Hasegawa A (2007) Subduction of the Philippine Sea plate beneath southwestern Japan: Slab geometry and its relationship to arc magmatism. Journal of Geophysical Research: Solid Earth 112(B8): B08306.

Nakamura A, Yokoyama Y, Maemoku H et al. (2012) Late-Holocene Asian monsoon variations recorded in Lake Rara sediment, western Nepal. Journal of Quaternary Science 27(2): $125-128$

Nakamura A, Yokoyama Y, Maemoku H et al. (2016) Weak monsoon event at $4.2 \mathrm{ka}$ recorded in sediment from Lake Rara, the Himalayas. Quaternary International 397: 349-359.

Nakamura Y, Nishimura Y and Putra PS (2012) Local variation of inundation, sedimentary characteristics, and mineral assemblages of the 2011 Tohoku-oki tsunami on the Misawa coast, Aomori, Japan. Sedimentary Geology 282: 216-227.

Nanayama F, Furukawa R, Shigeno K et al. (2007) Nine unusually large tsunami deposits from the past 4000 years at Kiritappu marsh along the southern Kuril Trench. Sedimentary Geology 200(3-4): 275-294.

Naruse H, Fujino S, Suphawajruksakul A et al. (2010) Features and formation processes of multiple deposition layers from the 2004 Indian Ocean Tsunami at Ban Nam Kem, southern Thailand. Island Arc 19(3): 399-411.

Nelson AR, Briggs RW, Dura T et al. (2015) Tsunami recurrence in the eastern Alaska-Aleutian arc: A Holocene stratigraphic record from Chirikof Island, Alaska. Geosphere 11(4): 11721203

Ota Y, Chappell J, Berryman K et al. (1997) Late Quaternary paleolandslides on the coral terraces of Huon Peninsula, Papua New Guinea. Geomorphology 19: 55-76.

Ozawa T, Tabei T and Miyazaki S (1999) Interplate coupling along the Nankai Trough off southwest Japan derived from GPS measurements. Geophysical Research Letters 26: 927-930.

Palmer AJM and Abbott WH (1986) Diatoms as indicators of sealevel change. In: van de Plassche O (ed.) Sea-Level Research. Dordrecht: Springer, pp. 457-487.

Parsons ML (1998) Salt marsh sedimentary record of the landfall of Hurricane Andrew on the Louisiana coast: Diatoms and other paleoindicators. Journal of Coastal Research 14(3): 939-950.

Pilarczyk JE, Dura T, Horton BP et al. (2014) Microfossils from coastal environments as indicators of paleo-earthquakes, tsunamis and storms. Palaeogeography, Palaeoclimatology, Palaeoecology 413: 144-157.

Pilarczyk JE, Horton BP, Witter RC et al. (2012) Sedimentary and foraminiferal evidence of the 2011 Tōhoku-oki tsunami on the Sendai coastal plain, Japan. Sedimentary Geology 282: 78-89.

Reimer PJ, Bard E, Bayliss A et al. (2013) IntCal13 and Marine13 radiocarbon age calibration curves $0-50,000$ years cal BP. Radiocarbon 55(4): 1869-1887.

Riedesel S, Brill D, Roberts $\mathrm{H}$ et al. (in revision) Single grain feldspar luminescence chronology of historical extreme wave event deposits recorded in a coastal lowland, Pacific coast of southern Japan. Quaternary Geochronology.
Saito H, Nanayama D and Matsuyama H (2010) Relationship between the initiation of a shallow landslide and rainfall intensity - Duration thresholds in Japan. Geomorphology 118: $167-175$.

Sakaguchi A, Kimura G, Strasser M et al. (2011) Episodic seafloor mud brecciation due to great subduction zone earthquakes. Geology 39(10): 919-922.

Sangawa A (2009) A study of paleoearthquakes at archeological sites. Synthesiology English Edition 2(2): 84-94.

Sangawa A (2013) Research results of earthquake-archaeology. Daiyonki-Kenkyu 52(5): 191-202.

Satake K (2015) Geological and historical evidence of irregular recurrent earthquakes in Japan. Philosophical Transactions of the Royal Society A 373(2053): 20140375.

Sawai Y and Nagumo T (2003) Diatom (Bacillariophyceae) flora of salt marshes along the Pacific coast of eastern Hokkaido, northern Japan. Bulletin of the Nippon Dental University 32: 93-108.

Sawai Y, Jankaew K, Martin ME et al. (2009) Diatom assemblages in tsunami deposits associated with the 2004 Indian Ocean tsunami at Phra Thong Island, Thailand. Marine Micropaleontology 73(1-2): 70-79.

Seno T (2012) Great earthquakes along the Nankai Trough - A new idea for their rupture mode and time series. Zisin 64: 97-116.

Shanmugam G (2012) Process-sedimentological challenges in distinguishing paleo-tsunami deposits. Natural Hazards 63(1): 5-30.

Shirai M, Omura A, Wakabayashi T et al. (2010) Depositional age and triggering event of turbidites in the western Kumano Trough, central Japan during the last ca. 100 years. Marine Geology 271(3): 225-235.

Shizuoka Prefecture (1996) History of Shizuoka Prefecture, No. 2. History of Natural Disasters. Shizuoka: Shizuoka Prefecture, $808 \mathrm{pp}$.

Silva-Sánchez N, Martínez Cortizas A and López-Merino L (2014) Linking forest cover, soil erosion and mire hydrology to late-Holocene human activity and climate in NW Spain. The Holocene 24(6): 714-725.

Sugiyama Y (1991) The Middle Pleistocene deposits in the Atsumi Peninsula and along the east coast of Lake Hamana, Tokai district - Sedimentary cycles formed by the glacioeustatic sea-level change and their correlations to the contemporaneous deposits in the Kanto and Kinki districts. Bulletin of the Geological Survey of Japan 42: 75-109.

Szczuciński W, Kokocinski M, Rzeszewski M et al. (2012) Sediment sources and sedimentation processes of 2011 Tohoku-oki tsunami deposits on the Sendai Plain, Japan - Insights from diatoms, nannoliths and grain size distribution. Sedimentary Geology 282: 40-56.

Takada K, Satake K, Sangawa A et al. (2002) Survey of tsunami deposits at an archaeological site along the eastern Nankai trough. Chikyu Monthly 24: 736-742.

Takashimizu Y, Urabe A, Suzuki K et al. (2012) Deposition by the 2011 Tohoku-oki tsunami on coastal lowland controlled by beach ridges near Sendai, Japan. Sedimentary Geology 282: 124-141.

Tanigawa K, Sawai Y and Namegaya Y (2016) Diatom assemblages within tsunami deposit from the 2011 Tohoku-oki earthquake along the Misawa coast, Aomori Prefecture, northern Japan. Marine Geology. Epub ahead of print 5 December. DOI: $10.1016 /$ j.margeo.2016.11.016.

Tanioka Y and Satake K (2001) Detailed coseismic slip distribution of the 1944 Tonankai earthquake estimated from tsunami waveforms. Geophysical Research Letters 28(6): 1075-1078.

Törnqvist TE, De Jong AFM, Oosterbaan WA et al. (1992) Accurate dating of organic deposits by AMS 14C measurement of macrofossils. Radiocarbon 34(3): 566-577. 
Tuttle MP, Ruffman A, Anderson T et al. (2004) Distinguishing tsunami from storm deposits in eastern North America: The 1929 Grand Banks tsunami versus the 1991 Halloween storm. Seismological Research Letters 75(1): 117-131.

Usami T (2003) Materials for Comprehensive List of Destructive Earthquakes in Japan. Tokyo: University of Tokyo Press, $605 \mathrm{pp}$.

Van Dam H, Mertens A and Sinkeldam J (1994) A coded checklist and ecological indicator values of freshwater diatoms from the Netherlands. Netherlands Journal of Aquatic Ecology 28(1): 117-133.

Van Geel B (1978) A palaeoecological study of Holocene peat bog sections in Germany and the Netherlands, based on the analysis of pollen, spores and macro-and microscopic remains of fungi, algae, cormophytes and animals. Review of Palaeobotany and Palynology 25(1): 1-120.

Van Geel B (2001) Non-pollen palynomorphs. In: Smol J, Birks HJB and Last W (eds) Tracking Environmental Change Using Lake Sediments, Volume 3: Terrestrial, Algal, and Silicaceous Indicators. Dordrecht: Kluwer, pp. 99-109.
Van Geel B, Coope GR and van der Hammen T (1989) Palaeoecology and stratigraphy of the lateglacial type section at Usselo (the Netherlands). Review of Palaeobotany and Palynology 60(1-2): 25-129.

Watanabe H (1998) Comprehensive List of Tsunamis to Hit the Japanese Islands. Tokyo: Tokyo University Press, 238 pp.

Williams HFL (2009) Stratigraphy, sedimentology, and microfossil content of Hurricane Rita storm surge deposits in southwest Louisiana. Journal of Coastal Research 25: 1041-1051.

Yokoyama Y, Anderson JB, Yamane M et al. (2016) Widespread collapse of the Ross Ice Shelf during the late-Holocene. Proceedings of the National Academy of Sciences 113(9): 2354-2359.

Yokoyama Y, Koizumi M, Matsuzaki H et al. (2010) Developing ultra small-scale radiocarbon sample measurement at the University of Tokyo. Radiocarbon 52(2-3): 310-318.

Yokoyama Y, Miyairi Y, Matsuzaki H et al. (2007) Relation between acid dissolution time in the vacuum test tube and time required for graphitization for AMS target preparation. Nuclear Instruments and Methods in Physics Research Section B 259(1): 330-334. 